Illinois State University

ISU ReD: Research and eData

Theses and Dissertations

$3-9-2014$

\title{
You Are That: An Upanishadic Approach to Empathic Writing Instruction in a High School Social Science Course
}

Andrew Otto Davis

Illinois State University, aodavis@ilstu.edu

Follow this and additional works at: https://ir.library.illinoisstate.edu/etd

Part of the Education Commons, and the History Commons

\section{Recommended Citation}

Davis, Andrew Otto, "You Are That: An Upanishadic Approach to Empathic Writing Instruction in a High School Social Science Course" (2014). Theses and Dissertations. 173.

https://ir.library.illinoisstate.edu/etd/173

This Dissertation is brought to you for free and open access by ISU ReD: Research and eData. It has been accepted for inclusion in Theses and Dissertations by an authorized administrator of ISU ReD: Research and eData. For more information, please contact ISUReD@ilstu.edu. 


\title{
YOU ARE THAT: AN UPANISHADIC APPROACH TO EMPATHIC WRITING INSTRUCTION IN A HIGH SCHOOL SOCIAL SCIENCE COURSE
}

\author{
Andrew Davis
}

120 Pages

August 2014

This dissertation reports the results of a qualitative research project investigating an approach to composition instruction in a high school social studies course that is based on the Upanishadic concept of tat tvam asi (you are that). Research for this study was conducted while the researcher taught a section of Non-West History to high school juniors and seniors. This dissertation addresses the issues involved in the teaching of writing in a high school social science course. Specifically it focuses on the issues involved when a teacher attempts to construct a class that engages students to read and write in ways that promote empathic understanding of the other. To make this argument, data were collected in Non-West History courses taught in 2012. This dissertation argues that writing in a social science class should not be limited to research papers and essay tests. Further, this dissertation agues (citing the work of Jeremy Rifkin, J. Krishnamurti, Carl Rogers, Rollo May, Thomas Merton, and S. Radhakrishnan) that writing assignments should also be given that promote the empathic awareness based on the Upanishadic concept of tat tvam asi-you are that. Further, this study offers an argument that writing in Social Studies classes should not be just about "conveying information" 
or "demonstrating knowledge" ( $c f$. Kiuhara et al. 150). Writing can be utilized to enhance a student's understanding of the complicated relationship that exists between the self and the other. 
YOU ARE THAT: AN UPANISHADIC APPROACH TO EMPATHIC WRITING INSTRUCTION IN A HIGH SCHOOL SOCIAL SCIENCE COURSE

ANDREW DAVIS

A Dissertation Submitted in Partial

Fulfillment of the Requirements for the Degree of

DOCTOR OF PHILOSOPHY

Department of English

ILLINOIS STATE UNIVERSITY

2014 
(C) 2014 Andrew Davis 
YOU ARE THAT: AN UPANISHADIC APPROACH TO EMPATHIC WRITING INSTRUCTION IN A HIGH SCHOOL SOCIAL SCIENCE COURSE

ANDREW DAVIS

COMMITTEE MEMBERS:

Janice Neuleib, Chair

K. Aaron Smith

Sarah Hochstetler 
ACKNOWLEDGMENTS

Thanks everybody.

A.O.D. 


\section{CONTENTS}

Page

ACKNOWLEDGMENTS $\quad$ i

CONTENTS

CHAPTER

I. INTRODUCTION 1

The Upanishads 4

II. STATEMENT OF THE PROBLEM: COMPOSITION

PEDAGOGY IN A NON-WEST HISTORY COURSE 13

$\begin{array}{ll}\text { The Basis: Something Else } & 14\end{array}$

Composing in a Non-West Course: Problems with the

Contact Zone Approach 16

$\begin{array}{ll}\text { Theoretical Lens } & 20\end{array}$

$\begin{array}{ll}\text { Multiculturalism } & 27\end{array}$

III. PEDAGOGICAL INFLUENCES AND METHODOLOGY 31

Composition Pedagogy 31

What I Really Value 33

Pedagogy and Philosophical Influences $\quad 34$

Carl Rogers, Rollo May, and The Dalai Lama 35

Data Collection Methodology 41

IV. THE UPANISHADS IN THE CLASSROOM 43

The Upanishad Assignment 43

$\begin{array}{ll}\text { The Project } & 48\end{array}$

$\begin{array}{lr}\text { Analysis } & 50\end{array}$

V. J. KRISHNAMURTI IN THE CLASSROOM 
$\begin{array}{ll}\text { The Prompt } & 62\end{array}$

Analysis $\quad 62$

Pedagogical Implications and Brain Research $\quad 67$

\section{THICH NHAT HANH AND THOMAS MERTON}

IN THE CLASSROOM

$\begin{array}{ll}\text { Thich Nhat Hanh } & 72\end{array}$

$\begin{array}{ll}\text { The Prompt } & 73\end{array}$

$\begin{array}{ll}\text { Analysis } & 74\end{array}$

$\begin{array}{ll}\text { Thomas Merton } & 79\end{array}$

$\begin{array}{ll}\text { The Prompt } & 81\end{array}$

$\begin{array}{lr}\text { Analysis } & 82\end{array}$

VII. "WAS JESUS A BUDDHIST?” A UNIT IN SECONDARY SOURCE ANALYSIS $\quad 89$

$\begin{array}{ll}\text { Was Jesus A Buddhist? } & 91\end{array}$

The Prompt 95

Analysis $\quad 96$

$\begin{array}{ll}\text { VIII. CONCLUSION } & 105\end{array}$

$\begin{array}{ll}\text { Recommendations } & 106\end{array}$

Restating the Research Questions $\quad 110$

$\begin{array}{ll}\text { Students Reflect on Their Understanding } & 111\end{array}$

$\begin{array}{ll}\text { WORK CITED } & 115\end{array}$ 


\section{CHAPTER I}

\section{INTRODUCTION}

This dissertation investigates an alternative methodology to the teaching of writing in a high school social science course that derives its pedagogical foundations not from the Contact Zone approach popularized by Patricia Bizzell, but rather one that derives from an understanding of the South Asian philosophy known as Advaita Vedanta. The core of this philosophy is founded on the concept of non-dualism and was first outlined in the ancient collection of texts known as the Upanishads with the phrase "tat tvam asi," which translated into English means "you are that."

The following three sets of questions serve as the foundation for this dissertation research:

1. How did students respond to reading and writing about the Upanishads? What were their reactions to the text and how did they express these reactions?

2. What creative insights did students show in their writings about other assigned texts? Why did they develop these insights and how does the evidence of their writing show these insights?

3. How does a course with a focus on Upanishadic non-dualism influence students to construct an identity based on empathic awareness? What do the outcomes of this pedagogical construction offer to teacher practitioners interested in crafting multicultural 
units that promote empathic awareness and a philosophy of unity through diversity? These research questions serve as the basis for this dissertation. The analysis chapters detail the outcomes of what can be learned by approaching a Non-West History course from this pedagogical framework.

A second component to this project derives from applying Jiddu Krishnamurti's suggestion that to fully understand and negotiate our identities we must acquire an understanding that our lives are often based on conditioning and fragmentation. Thus, a second set of research questions informs this dissertation:

1. How do students respond to a Non-Western (Krishnamurtian) approach to social interactions and learning situations?

2. What can be learned from asking students to read outside their comfort zones?

According to Krishnamurti people are conditioned to view the self and the other as being different. This can lead to us to living fragmented lives based on inaccurate dualist constructs of identity. Once a person recognizes this conditioning they may overcome the fragmentation and live a more meaningful, non-dualist existence based on the recognition that the self is the other. Many in the West find this ontological framework difficult to comprehend and the students participating in this study were no exception. Unlike in the Contact Zone model which asks students to "grapple" over diversity for the purpose of illustrating the dramatic cultural differences around the world, the Upanishadic approach encourages students to reflect on texts in a way that creates empathic awareness that the self is the other. This dissertation links these findings to developing theories in brain research on mirror neurons. For example, Marco 
Iacoboni argues in his text Miirroring People: The Science of Empathy and How We Connect with Others that the "self and other are blended in mirror neurons..." (152). He further argues that current brain research into mirror neurons illustrates "the biological roots of intersubjectivity. Unfortunately, philosophical and ideological individualistic positions especially dominant in our Western culture have made us blind to the fundamentally intersubjective nature of our own brains" (Ibid.). Iacoboni's lamentation about the complexities involved in theorizing about the self and the other from a nonWestern philosophical orientation is echoed in this dissertation. Later chapters will address these complexities. Similarly, George Lakoff argues in his text The Political Mind: Why You Can't Understand $21^{\text {st }}$ Century American Politics with an $18^{\text {th }}$ Century Brain that conceptual metaphors that influence how we think morally impact our overall well-being. He concludes "In short, when we do good, we feel good—we feel a sense of well-being...In addition, mirror neuron and associated research tells us that we are born with a capacity for empathy" (101). A significant question becomes: What new insights can composition practitioners gain by creating assignments based on the Upanishadic concept of non-dualism in light of Upanishadic philosophy and current trends in brain research? These questions are addressed in the Krishnamurti chapter of this dissertation.

Because many people in the West possess no familiarity with the Upanishads the following section offers a brief description of these texts and their place in the history of thought. Lakoff and Johnson make this point repeatedly in Metaphors We Live By. They point out multiple places in their text that "Western culture" and "Western philosophy" are bound to what they term the "myth of objectivism" $(195 ; c f .143,145-146,159,182$, and 197). They, instead, offer what they term the "experientialist" view that posits that 
"metaphorical imagination" can create a moment where one can "blend your world view and adjust the way you categorize your experience" (231). This dissertation argues that an understanding of the Upanishads can aid students in the creation of this kind of metaphorical imagination as they negotiate their identity construction. This introduction concludes with an outline of the dissertation and an explanation of the specific research questions and goals involved in this overall project.

\section{The Upanishads}

The collection of texts known as the Upanishads consists of commentaries on the earlier Vedas which comprise the foundational texts for the Hindu world view and thought. They were written in India over several hundred years between about 800 and 200 BCE (Herman 83). To contextualize it in European terms, most of the Upanishads were written between the time of Homer and just after that of Aristotle. These texts were written in Sanskrit and meant to elaborate on the teachings of the sacred texts collectively known as the Vedas. As A.L. Herman points out in An Introduction to Indian Thought, these collections of mystical verses were not just religious in nature. They were, in fact, insight into the metaphysical and epistemological world in which the people of South Asia lived. These texts are philosophy. Their concepts, notions of the self, the world, knowledge construction, and understanding of truth are relevant for us today. This text dramatically impacted the pedagogy employed in this study especially when theorizing about composition in a history class.

In the Afterward to Eknath Easwaran's translation of several key Upanishads, Michael Nagler summarizes and provides explanations for the insights of the texts. The 
strength of the Upanishads lies in the nonjudgmental way that they "offend neither our sense of logic nor our sense of responsibility for discovering truth for ourselves" (296). Therefore the philosophy of the Upanishads recognizes that "knowing is not a separate activity from other aspects of being_courage, endurance, concentration, will..." (315). This illustrates the "transcendent" nature of knowledge. One must recognize this through "knowing which, all things are known" (Ibid.). He suggests that "ordinary knowledge is either subjective or objective; transcendent knowing is neither" (Ibid.). Thus, "the only way we can truly know something is to become identified with it" (Ibid.). As it is expressed in Upanishadic logic, tat tvam asi "You are That." Or, as the Katha Upanishad states:

When the five senses are stilled, when the mind is stilled, when the intellect is stilled. That is called the highest by the wise... The unitive state cannot be attained through words or thoughts or through the eye. How can it be attained except through one who is established in this state oneself?

Or in the Chandogya Upanishad:

Control the senses and purify the mind. In a pure mind there is constant awareness of the Self. Where there is constant awareness of the Self, freedom ends bondage and joy ends sorrow.

Raimundo Panikkar in The Vedic Experience suggests that the "personal character of reality is stressed in Advaitic world view" (747). The Upanishads are the key texts in Advaida literature. In this world view "The real person is beyond the singular and the 
plural...Person is a net of relationships" (Ibid). This is the beauty of Tat tvam asi. Thou art that. Thus, "the clue to the mystery of the person is the thou. Without thou there is no $I$...There is only an $I$ when he is capable of uttering, discovering, creating, a thou...The $I$ and the thou encounter each other in the he/she/it of the third person...This gift of the thou is the third person, the other, the world, the interval in which my being reaches its fulfillment responding to the $I$. The third person is the gift; there is here not a dialectical but a free dialogical relationship" (Ibid). The reader should not confuse this position with Martin Buber's concept of I and Thou. Buber argued that the world is made up of I-You relationships where the I and the You act in a relationship of reciprocity (67). In Upanishadic philosophy, the I is the Thou (this is also the basis of Auldous Huxley's Perennial Philosophy).

Sri Chinmoy suggested that the Upanishads "offer us self-knowledge" and “world-knowledge...." For Sri Chinmoy, "Self-knowledge is self-discovery. After selfdiscovery we have to feel that world-knowledge is within us, and we have to grow into world-knowledge" (56). Sarvepalli Radhakrishnan, a philosopher of modern India who also studied in the West and wrote about the relationship between Eastern and Western thought, suggests that in the East the emphasis is generally on the "ultimacy of creative Intuition and that the West lays emphasis on critical Intelligence” (Kumar Lul 297). Radhakrishnan suggests a view that is similar to that of J. Krishnamurti which he calls "Intuitive Apprehension" (Ibid.). Thus, the "Intuitive apprehension of the knower establishes an identity with the known." (Ibid.). Through this approach we can become "one with the truth, one with the object of knowledge. The object known is seen not as an 'object outside the self, but as a part of the self'" (Ibid.). For this reason 
Radhakrishnan's philosophy of being is often described as monistic idealism.

Ontologically, monism simply means that there is only one existent thing. Sue Hamilton (29) reminds us that monism should not be confused with monotheism which is the idea that there is only one God. And Kumar Lal (259) clarifies, "It is monistic because reality is conceived as one..." For Radhakrishnan, one knows "by becoming" (Ibid.).

J. Krishnamurti, in an essay titled Can We Understand Ourselves? pondered the possibility to go beyond the things measured by the mind allowing us to live "without any illusion" (The Awakening of Intelligence 319). For him, the fragmentation and division that permeate our existence when we focus on the empirical aspects of knowing and not true knowing blinds us with illusion. He asks, "is it possible to look at ourselves non-analytically and therefore observe without the 'me' observing?" He continues by suggesting that it is the 'I' that gets in the way of truth. He suggests, "If there is the observer looking then he must look through fragmentation, through division and where there is division, both myself and outwardly, there must be conflict...So, if in looking there is this division as the 'I' and the 'not I', as the observer and the observed, as the thinker and the thought, as the experiencer and the experience, then there must be conflict" (Ibid.). In a debate with Swami Venkatesananda he put it differently. "I don't like to use 'subjective' and 'objective'. Is there need of experience at all? We have said: experience is the response to a challenge" (Ibid. 167). For Krishnamurti, the challenge is based on a duality that does not exist, and it is driven by division and fragmentation which makes knowing impossible. Consider his interpretation of the term analysis. $\mathrm{He}$ states, "And in analysis there is the analyzer and the analyzed...There is this duality, the analyzer analyzing something which he thinks is different from himself...so in the 
process there is conflict" (Ibid. 61). For Krishnamurti, analysis prevents action. It makes reality unknowable because when one analyzes one must draw on memories, which for Krishnamurti are based on the past. Thus the difficulty becomes the complexities involved when one tries to understand the present based on memoires of the past. The question becomes: "Is there a way to observe the "whole content of consciousness without the analyzer?'” (Ibid. 64).

This conflict, created by an understanding based on duality, creates illusion ( $m \bar{a} y \bar{a}$ in Sanskrit). This occurs when the observer separates "himself from the thing he observes..." (Ibid.67). Conflict is the suppression, conformity, imitation and all similar outcomes that occur under this dualist version of reality. If one wants to see past the illusion created by conflict, to see the whole content instantly, one must recognize that the observer is the observed, "the two are not separate" then one can "observe the totality of consciousness without analysis" (Ibid.). The real problem is that thought conditions us to this separation, division, fragmentation. In a dualist system, thought leads one to conclude that a division actually exists between the 'I' and the 'not I'. Krishnamurti suggests that one must realize "there is no division between the observer and the observed, between the thinker and the thought...then you observe actually 'what is'. And when you see actually 'what is', you are already beyond it” (Ibid 69). Once this move has been made it becomes possible to understand "that we are the world and the world is us. The world is each one of us" (Ibid. 75). In this regard everything comes down to relationship, as Krishnamurti made clear when he stated "because relationship means to be related — not in action, not in some project, not in an ideology—but to be totally united 
in the sense that the division the fragmentation between individuals, between two human beings, does not exist at all at any level" (Ibid. 76).

The concept of $m \bar{a} y \bar{a}$ can be problematic for many readers of the Upanishads. Translated loosely it means "illusion." Arthur Schopenhauer often cites what he calls "the veil of māyā" when he describes the world as a representation of the mind.

However, Gaudapada's use of $m \bar{a} y \bar{a}$ is more appropriate for this study because it is more in line with the way Krishnamurti might recognize illusion. Gaudapada interprets $m \bar{a} y \bar{a}$ as that event when one finds "differences where none exist..." (Potter 68). Or as Swami Nikhilananda (500) suggests, "The Upanishads do not deny the reality of the world. They allow it an empirical reality. As long as a man is conscious of multiplicity, he must deal with it as real." This seems to conform to the monistic view described earlier in this chapter. Like Krishnamurti who believes that the world could be understood, Radhakrishnan argues that the ancient Vedic thinkers understood this as well. Contrary to many modern interpretations of $m \bar{a} y \bar{a}$ as represented in the Upanishads, he argues, "Māyā does not mean that the empirical world with the selves in it is an illusion..." (Radhakrishnan cited in Moore 303). Further, "The manifold universe is not an illusion; it is being...The world is not a deception but the occasion for it" (Ibid). This concept becomes quite complicated if we accept the premise of tat tvam asi: "Thou art that." As A.L. Herman argued in An Introduction to Indian Thought, "There is only one being but it is called by two names, hence the properties of one must be the properties of the other" (Herman 122). Each point to the same "ultimate reality." "The world is you and me, the world is not separate from you and me..." (Krishnamurti Total Freedom 289). Here Krishnamurti embraces tat tvam asi. 
Krishnamurti offers a theoretical orientation that can enhance an approach to pedagogy based on an Upanishadic construction of existence in relation to a composition pedagogy that encourages empathic awareness. He surmises "So we are dealing with the human, global problem, which is that you as a human being are living in a disintegrating world. So when we talk about relationship we are talking about the relationship of man to man...Unless you have a global, universal sense of the whole human being, you will live merely in fragments...We are concerned with mankind [sic], which is you."

Importantly, Krishnamurti argues that one must, "understand one's self in relationship with another. Then relationship becomes not a process of isolation but a movement in which you discover your own motives, your own thoughts, your own pursuits; and that very discovery is the beginning of liberation, the beginning of transformation" (The First and Last Freedom 107). Similarly, Mahatma Gandhi's theory of "heart unity" that fosters the idea of "Unity in diversity" is a major theoretical component of this dissertation (Easwaran 329). The question then becomes: What might be writing's role in this "transformation" that can lead us to understand the world through the understanding of the self? The observer is the observed. The 'other' is the 'I.' This is a very different view than Fecho et al. (126) suggest when they argue that writing can be used to develop self and cultural identity, or Donna Qualley's (14) theory that reflexivity in student writing can make us "self-conscious, cognizant of our roles in the production of knowledge." It is also different than Nick Tingle's (154) observation that the role of the writing instructor becomes to assist "students in their self-development..." Derek Owens (69) in his text Composition and Sustainability comes closer when he suggests that educators "have a responsibility to help students resist the cynicism and 
hyperboredom of contemporary, consumer culture by discovering the kind of self-worth that comes from being amazed at one's local worlds." His argument is based on a premise similar to the one taken in this dissertation. For Owens, the notion that the self and the world are separate creates a "misconception" (69).

The Upanishads provide the pedagogical foundation for this dissertation. This introductory chapter provides a brief historical and philosophical outline of the Upanishads to familiarize the Western reader who may not have ever experienced an epistemological non-dualist construction of identity.

Chapter one problematizes various approaches to composition theory focusing specifically on Raúl Sánchez's text The Function of Theory in Composition and Mary Louise Pratt's vision of a "contact zone." In reviewing this literature the chapter outlines how many practitioners approach teaching multicultural literature. This establishes a baseline which serves to illustrate how the Upanishadic approach developed for this dissertation research derives from a very different epistemological orientation.

Chapter two provides a description of the data collection methodology and briefly describes how this methodology relates to this study's approach to composition pedagogy. This chapter also provides a discussion of several thinkers that influenced the ontological foundation for the way this Non-West history course was taught.

The next several chapters provide an analysis of the various writings students produced based on assigned prompts. Chapter three provides an analysis of student responses to a presentation they did and writing prompt they each responded to in an online blackboard course discussion board on an assigned Upanishad. The discussion 
relates this assignment to the work of Kathleen Blake Yancey and her call that teachers use composition to help create citizens of the world.

Chapter four provides an analysis of the writing students produced after studying the work of J. Krishnamurti. The chapter relates in the discussion section how current trends in brain research (specifically the discovery of mirror neurons) support the importance of using Krishnamurti's work in a writing course promoting empathic awareness.

Chapter five provides an analysis of student writing after they studied the work of Buddhist monk Thich Nhat Hanh alongside the writings of Catholic monk Thomas Merton. The analysis illustrates how students responded to texts written by a Buddhist and a Catholic, both writing about the self and other. The chapter concludes by filtering the results through Maxine Hairston's paper “Diversity, Ideology, and Teaching Writing."

Chapter six provides an analysis of student writing in response to what historians refer to as a "secondary source." In this chapter the assigned text is a piece of academic literature, an article by James Hanson called "Was Jesus a Buddhist?" This chapter analyzes student writing through the lens of composition theory and pedagogies currently popular in history education pedagogy. 


\section{CHAPTER II}

\section{STATEMENT OF THE PROBLEM: COMPOSITION PEDAGOGY IN A NON-WEST HISTORY COURSE}

Scholars in the field of composition often debate the lack of critical thinking in many high school students. Researchers note that students are often times unsure of what is expected of them as writers and unable to negotiate paths of knowledge construction through writing. In a recent study by Kiuhara et al. titled "Teaching Writing to High School Students: A National Survey" published in the Journal of Educational Psychology researchers found that teachers mostly ask students to write to convey information or demonstrate their knowledge. Teachers indicate that they seldom ask students to write to "develop new insights, clarify information, examine personal experiences, stretch the imagination, or persuade others" (150). The question for teachers of writing becomes: How can students learn to go beyond information acquisition and on to the complex processes of thinking and reasoning for themselves. Certain types of Eastern epistemologies can open these complexities of thought to students; this chapter explains how those complexities can sharpen and deepen student thinking and writing.

This chapter addresses the problems posed by Kiuhara et al. Specifically, it problematizes and analyzes a different approach to the use of writing in a high school Non-West History class_- one that motivates students to strive for insight and empathic awareness through writing. The pedagogical approach suggested here is based on the 
Upanishadistic premise of Non-Dualism which leads to an empathic understanding that allows students to re-negotiate the self in a way that leads not just to better selfunderstanding but also to other-understanding. This is a different model than that put forward by the Contact Zone pedagogy advocated by Patricia Bizzell and Mary Louis Pratt and mainstream approaches to multiculturalism which so many in composition studies and multicultural education suggest such as Min-Zhan Lu, Paul Gorski, and Pepi Leistyna. The differences are dramatic and teacher practitioners, whether in English or in history will find a model offered here that will challenge them to re-evaluate the possibilities for pedagogical applications to incorporating writing in their courseswriting instruction can be about creative insight and empathic awareness as well as critical thinking.

\section{The Basis: Something Else}

Raúl Sánchez, in his text The Function of Theory in Composition Studies, critiques several philosophical and critical positions dealing with the nature of writing and interpreting texts. Sánchez suggested that "Composition theory begins to mark the next step in the writing subjects' progress when it redefines the writing subject not as a producer of writing but as a function of writing itself" (83). He then argues that there has been an over-emphasis in composition theory on how readers "interpret" texts as opposed to how writing itself is a "paradigmatic feature of human being" (90). This leads him to conclude that it becomes necessary to "displace the interpretive stance at the core of composition studies' implicit (and sometimes explicit) dispositions toward writing, which identify it as a technology, as a means of conveying or producing something else" (91, emphasis in the original). Further, he equates the "quest for something else" as it is 
achieved through discourse to be a product of the modernist "quasi-heroic" author struggling to make meaning through textual production (38). He cites Janet Emig's "writing-as-learning thesis" as an example, and although he never uses the term, in pedagogical theory it is "constructivism" that he asserts to be flawed here. For constructivism to work, it must be accepted that the something else that is created through textual production is knowledge. As he made clear that the construction of knowledge through writing is limiting when he states, "When composition theorists invoke knowledge or knowing as an important result of writing, we continue to participate...in a historical discourse that can only articulate writing as precisely the handmaiden of knowledge" (32). The impact of these conclusions challenges a controversial belief among practitioners. Can writing produce the knowledge of something? Throughout his text Sánchez offers insightful reviews of many key texts in composition and theoretical literature but a limitation to his text is that no new theoretical orientations or practical methodologies are offered in regards to composition pedagogy.

Kathleen Blake Yancey is correct: we have a moment. While her Writing in the 21 st Century focuses largely on the role of new technology in the teaching of writing she makes three suggestions (she calls them the "challenges that we currently face") that inform this dissertation: First, we are in need of developing new models of composing. Second, we must design a new curriculum supporting those models. Finally, we need to create new pedagogies enacting that curriculum. Thus, this study focuses on compositionist and pedagogical goals that facilitated writing engagements which challenge students to negotiate their concepts of self and other through creative thinking. Specifically the non-dualistic view of existence that leads to the empathic understanding. 


\section{Composing in a Non-West History Course: Problems with the Contac Zone}

\section{Approach}

Teaching Non-West History to high school juniors and seniors at first appeared to be an opportunity to employ the Contact Zone approach. The texts students read and the films that students viewed create spaces "where cultures meet, clash, and grapple with each other..." (Pratt 34). For Pratt, "The idea of the contact zone is intended in part to contrast with ideas of community that underlie much of the thinking about language, communication, and culture that gets done in the academy" (35). This approach leads her to conclude that it is the job of teachers to "figure out how to make that crossroads the best site for learning that it can be" (40). Pratt's methodology was picked up and expanded by Patricia Bizzell leading her to suggest that the "contact zone" should be the basis for a "radically new system" that would redefine English Studies. There are multiple reflections on the contact zone since Pratt's initial essay (see David Bartholomae's “The Tidy House: Basic Writing in the American Curriculum.” $c f$. Jon Stratton and Vijay Devadas's "Identities in the Contact Zone;" Robin Boast's "Neocolonial Collaboration: Museum as Contact Zone Revisited;" and Min-Zhan Lu's influential "Professing Multiculturalism: The Politics of Style in the Contact Zone"). Patricia Bizzell extended the definition of the "contact zone" by suggesting that it should be "primarily defined in terms of historical circumstances" (166; emphasis mine). She further suggests that English Studies should be completely re-envisioned "in terms of historically defined contact zones" (167). Pratt is correct that much of the thinking about teaching and learning in the academy can be stifling. The question becomes: Am I going to use texts and writing assignments to illustrate spaces where cultures meet, clash, and 
grapple with each other...? And at a deeper level, should the course promote the idea of “difference as an asset?" (Bizzell 166). The concept of "difference” as used in this context becomes a drawback. It is not suggested in this dissertation that Pratt's contact zone approach or Bizzell's argument that English Studies would benefit from coming to terms with multiculturalism, is a negative outcome. On the contrary, these approaches have brought about very positive changes to English Studies Departments over the last 25 years and to high school social studies courses. It should also be noted that there have been several meaningful approaches to the contact zone in a diversity of fields-from libraries ( $c f$. James Elmborg's "Libraries in the Contact Zone: On the Creation of Educational Space”), to museums ( $c f$. Robin Boast's “Neocolonial Collaboration: Museum as Contact Zone Revisited"), to the World Social Forum ( $c f$. Janet Conway "Cosmopolitan or Colonial? The World Social Forum as 'Contact Zone”"), even research that occurs across intercultural boundaries ( $c f$. Catherine Manathunga's "Research as an Intercultural 'Contact Zone"'), and finally to the study of identity in the postmodern world ( $c f$. Jon Stratton and Vijayu Devadas "Identities in the Contact Zone). However, operating under an ontological framework based on Upanishadic non-dualism and not a Foucaultian binary, the contact zone methods of analysis are not appropriate for the internship course developed for this study and in fact work to create conflict that is counter to the philosophical foundation of the Upanishads. When utilizing the Upanishad texts no space exists for the rhetoric of binaries and conflict in any pedagogy that encourages students to negotiate identities between the self and the other.

In a positive critique of the "contact zone" Matthew Abraham argues with Bizzell that the academy needs to reflect on how "Writing, as rhetoric of resistance, allows for a 
transcendence of the conditions that stifle human life, particularly in instances where we, as academics, are complicit in creating the conditions responsible for such dehumanization" (136). Too much focus on "difference" can lead students not to the appreciation of the other but to the dehumanization of the other. The composition pedagogy employed in this study explores an alternative to Bizzell's contact zone approach — an alternative that did not focus on the "difference as productive" model (Manathunga 165). Yet Manathunga's warns that there can be a "liberal tendency to minimalize or disavow difference, where authors argue that the needs of all students are the same regardless of culture" (165). Manathunga's critique that "Disciplinary canonical knowledge tends to marginalize Eastern and Indigenous knowledge and discourses" is apt (171; $c f$. Canagarajah's "Resisting Linguistic Imperialism in English Teaching”). Pedagogical considerations in regards to reading and writing that are modeled in this dissertation are not about dwelling on the "difference," the writing prompts that inform the data collection are designed to engage students and aid them in the recognition of oneness as based on the Upanishads. Language does not always need to be viewed as a "site of struggle" as Min-Zhan Lu argued in her essay "Professing Multiculturalism: The Politics of Style in the Contact Zone.” And James Berlin states that "every pedagogy is imbricated in ideology..." (735).

Through operationalizing Upanishadic concepts founded on unity the data collected for this dissertation problematizes the methodology of the Contact Zone as a pedagogical approach. The teaching of literature, philosophy, history, and writing can be enhanced by focusing on composition's role in generating Upanishadic empathic understanding — not conflict between self and other as prescribed by the contact zone. 
Jeremy Rifkin has suggested recently that "Because empathic skills emphasize a nonjudgmental orientation and tolerance of other perspectives, they accustom young people to think in terms of layers of complexity and force them to live within the context of ambiguous realities where there are no simple formulas or answers, but only a constant search for shared meaning and common understanding" (15-16). Further, cognitive scientists are now arguing that parts of the brain are composed of "mirror neurons" (see specifically Iacoboni's text Mirroring people: The New Science of how we Connect with Others, and Hollan's Emerging Issues in the Cross-Cultural Study of Empathy. The evidence emerging from this new field of study has led George Lakoff to recently suggest that "we are born with a capacity for empathy...In short; we are not just pre-wired for empathy, but for cooperation" (101). This theoretical framework is not only beneficial to the teaching of writing but also to a student's understanding of history and culture. As James Loewen (of Lies My Teacher Told Me fame) argued, history courses should be about "empathetic understanding" (87). He submits that historians utilize what the Germans call verstehende. Loewen suggests that utilizing verstehende can lead students to step inside the shoes of someone else and imagine "how they see the world and what they would do" (87). It is for these reasons that in a recent TED speech Karen Armstrong asks her audience to move past "tolerance" and move toward "appreciation" (she makes this point in her text Twelve Steps to a Compassionate Life as well). Thus, the data (student writing samples) analyzed in this dissertation is designed to illustrate an epistemology constructed through a lens based on a praxis infused with J. Krishnamurti's and Thomas Merton's ontology. In other words, the Upanishad concept of tat tvam asiYou are That—which is so evident in the work of Krishnamurti and Merton. This non- 
dualist view of being frees us from the framework of wanting to promote oneness at the expense of conformity or racial insensitivity. As Subrahmanya Iyer stated "Non-duality does not mean the non-existence of a second thing, but its non-existences as other than yourself..." (69). This shift in ideology has a dramatic impact on the teaching of writing in a Non West History course.

\section{Theoretical Lens}

As a high school history teacher who teaches Non-West History, a research goal is to develop a theory of writing that helped create an experience for students that is not an "exercise in conformity” (Redd 74). Raúl Sánchez offers a starting point when theorizing about composition and the something else that is created through writing. Mary Louise Pratt and Patricia Bizzell challenge theories of how students negotiate texts in the "contact zone" of the classroom through focusing on what Homi Bhabha calls "difference" (44). Yet, when one confronts the texts of Non-Western philosophers like J. Krishnamurti and S. Radhakrishnan as well as the Upanishads, one will recognize that a pedagogy that focuses on the dialectics of "difference" leads to fragmentation and confusion for students. It is through this new theoretical lens, one that asks students to recognize the other in the self that has driven this study's theorizing about the role of composition in the production of the "something else." This Upanishadic approach is really not new. bell hooks discusses her discovery of Thomas Merton in her seminal text Teaching to Transgress: Education as the Practice of Freedom. hooks asserts that for Merton, "Cultural and doctrinal differences must remain, but they do not invalidate a very real quality of existential likeness...True communication on the deepest level is more than a simple sharing of ideas, of conceptual knowledge, or formulated truth. The 
kind of communication that is necessary on this deep level must also be 'communion' beyond the level of words a communion in authentic experience..." (175-176). For hooks, this space is where "professors can best teach..." (hooks 199). This dissertation suggests a different approach to kairos. One based not on "communication" but on "communion." Once students understand this—-that their writing is not just about showing how many facts they know, but about communing with the "other" in a way that leads to an understanding of the "self." At that moment, empathic awareness might be created. Or as the ancient authors of the Upanishads would say, "You are that." This is the significance of kairos. It is both the special and the temporal context of the moment (Sheard 291). The ancient Greeks (specifically the Protagoreans and the school of rhetoric that developed around the teaching of Gorgias; $c f$. Carter 102-103; and Kinneavy 14) viewed kairos as that "critical point in time and space" that created a "sense of rightness" and lead to harmony and "conflict resolution" (Carter 102). This was a relativistic harmony between bodies sharing a moment. It blends well with Krishnamurti's position that "if you listen argumentatively, then it is fairly clear that there can be no understanding...that actually prevents the understanding or discovery of the truth in what is being said" (Krishnamurti Total Freedom 178-179). This dissertation offers a pedagogy based on a praxis of non-duality infused with a view of kairos that embraces the communion between the self and other that leads to a moment of empathic awareness—-tat tvam asi.

In developing this project certain complexities began to emerge that illustrate the difficulty of navigating away from binaries. For example, the course was titled "NonWest History." This title suggests a binary: West and Non-West. The title of the course 
should be changed to better reflect the philosophical foundations employed in the teaching of the course. Other dichotomies emerge as well through-out this study that illustrate the rhetorical complexities of attempting to offer a different or alternative view that promotes what might be termed non-difference or more specifically non-dualism. Lakoff and Johnson's text Metaphors We Live By helps in re-thinking these issues. They argue that "most of our normal conceptual system is metaphorically structured" (56). Thus, it becomes difficult for a person to understand anything without relying on metaphor. They see metaphorical concepts as "ways of partially structuring one experience in terms of another" (77). This is important to understand because "a concept fits an experience (83). Because metaphor plays a key role in the way we function and conceptualize our experiences (115) and that these conceptual frameworks shape the way we experience the world a course designed to challenge the rigidity of certain metaphors could create what Lakoff and Johnson call "open-ended" experiences (125.

In re-thinking an approach to the teaching of this course overcoming the binaries and conceptual systems of thought became a challenge. The cultures studied in this course would no doubt not self-identify as "Non-West" because it implies a negative connotation where the "West" is privileged. Thus the very title of the class is a mistake. Metaphorical interpretation, as Lakoff and Johnson point out, varies culture to culture as well and this aspect conceptualizing metaphor can lead to productive results in a course like the one developed here. As they argue, having experiences with the other leads to new metaphors being created in the self. For Lakoff and Johnson, "New metaphors have the power to create a new reality" (145). This happens when a person starts to comprehends experiences in terms of metaphor. When new metaphors enter the 
conceptual system in this way cultural change arises "from the introduction of new metaphorical concepts and the loss of old ones" (Ibid.). On one level this study attempted to overcome binaries which required the examination of binaries. And while the structure of the methodology perhaps fell short due to the paradoxical nature of the approach, Lakoff and Johnson do conclude that "changes in our conceptual system do change what is real for us and affect how we perceive the world and act upon those perceptions" (145-146). It is difficult to operationalize a pedagogical approach to teaching based on "unity in diversity" (Gandhi's phrase) but the ultimate outcome discussed in the analysis chapters illustrates Lakoff and Johnson's argument that being exposed to new metaphors from cultures other than one's own can lead to the changing of a person's conceptualization of the self and other.

The problem faced by many teachers of writing in multicultural pedagogical spaces, the one Sánchez expresses in his critique of the "something else," is difficult to approach relying on the standard theories that many teachers tend to use when constructing an understand of the world. It is deeper than a rejection of Continental philosophies and their offshoots. Lyotard's vision of the post-modern will not help construct a better model. The postmodern perspective is all about "différend within which the fate of thought has, for a long time, been played out, and will be continued to be played out" (13). Nor are we reflecting on Heidegger's (355) “worldless subject." Which leads Barbara Couture to observe that this Heideggerian view led Lyotard to reject "the peaceful pursuit of a unity that dissolves differences..." (177). in this current movement, the focus must be on unity. Further, as Byron Hawk (217) recently suggested, "What is needed is a model of the subject that responds to rhetorical 
exigency." This model is problematic under current orientations and will be difficult to achieve with our current reliance on Aristotle's concepts of rhetoric. Patricia Bizzell once called for a "radically new system to organize English studies..." (480). But her reliance on "contact zones" has been problematic for anyone attempting to rethink multicultural educational possibilities.

To illustrate this point, an examination the Writing Program Administrators (WPA) Outcomes for First Year Composition (FYC) instruction is in order-specifically, the first two: Rhetorical Knowledge and Critical Thinking, Reading and Writing. By the end of a student's first year of college writing, they should have the following rhetorical knowledge and skill set:

- $\quad$ Focus on a purpose

- $\quad$ Respond to the needs of different audiences

- $\quad$ Respond appropriately to different kinds of rhetorical situations

- Use conventions of format and structure appropriate to the rhetorical situation

- $\quad$ Adopt appropriate voice, tone, and level of formality

- Understand how genres shape reading and writing

- Write in several genres

Students should also understand the following critical thinking concepts:

- Use writing and reading for inquiry, learning, thinking, and communicating 
- Understand a writing assignment as a series of tasks, including finding, evaluating, analyzing, and synthesizing appropriate primary and secondary sources

- Integrate their own ideas with those of others

- $\quad$ Understand the relationships among language, knowledge, and power

It seems that Sánchez (and many other composition theorists) base their theories on writing and pedagogy on the outcomes that should occur if students have been taught to write using the above objectives. Western concepts of epistemology are based on theories of critical intelligence. This ability to think critically that is so cherished is based on the same Hellenistic foundation as the above mentioned writing goals. Yet, for the alternative methodologies elaborated on in this dissertation, the emphasis is on creative intuition and harmony (note: one way of translating kairos from the Greek is "harmony"). A look at what is missing from the WPA Outcomes is informative in this regard: There is no mention of harmony (and while it could be argued that understanding the relationships "among language, knowledge, and power" might lead to a kind of harmony simply understanding the relations between language and power does not necessarily promote empathic awareness). At no point is empathic understanding addressed. This current rhetorical allegiance makes no real space for understanding the relationship of the self to the world. Seen in this light, it seems clear that at a fundamental level a reliance on Greek notions of rhetoric and knowledge predispose us to never be able to realize the something that is else. The philosophies Sánchez deconstructs, the theories, empirical research, and analyses examined in The Function of Theory in Composition Studies 
become limited by this fact. To subscribe to Krishnamurti's concepts (especially those dealing with conditioning and fragmentation) then the conclusion is clear-the very nature of Sánchez's approach becomes the problem. When a rhetorical approach is based on conflict it quickly becomes clear why Krishnamurti's and Merton's views might enable our search for the something else to go further. As Radhakrishnan (632) quotes from the Katha Upanishad in his discussion of self and the world, "He who has not first a peaceful mind," cannot reach truth. Greek rhetorical approaches are steeped in conflict (much like the contact zone model), and it becomes difficult for the mind to achieve peace and truth. This study suggests that Upanishadic epistemology can benefit teachers of writing and composition theorists in this regard. The WPA outcomes illustrate this Western bias. In this case the bias is not a negative thing in itself. These concepts are based on Western composition pedagogies and concepts of rhetoric. Since many of our concepts of rhetoric are based on confrontation and persuasion we tend to embrace a rhetorical theory that places us squarely into what Paulo Freire calls the banking model of education. The very act of persuasion implies that the speaker or writer believes they have superior knowledge that others must accept and conform. It is an approach based on hierarchy and at its heart the idea that I, as the writer, know what is best for you, the reader. This creates a dialectic, and thus, an ontology grounded in conflict.

This dissertation offers a different approach to the contact zone in a way that created a different way to theorize about composition specifically because the course did not dwell exclusively on Western thinkers. It is interesting that in calls for multiculturalism in education, the focus always seems to be about literature. There is rarely a mention of philosophic orientation. It is not just a turf war in English Studies. 
The issue at present becomes one of relationship—and the lack thereof. Radhakrishnan once wrote, "There is no reason to believe that there are fundamental differences between the East and the West. Human beings are everywhere human...East and West are geographical expressions and not cultural types" (The Indian Approach to the Religious Problem 255). In this expressive spirit a moment emerged to reformulate the rhetorical theory used in the teaching of writing in this Non-West History courses.

\section{Multiculturalism}

The issue of multiculturalism needs to be addressed. As argued in this dissertation, the focus on difference and tolerance also needs to be reevaluated. We, as educators, have focused so much pedagogical attention on difference that something has been lost. This long standing practice of highlighting difference could benefit from also recognizing the significance of common humanity.

There are many wonderful facets to multicultural education. And, the impact on teachers and students has no doubt been beneficial (cf. Sonia Nieto's text Affirming Diversity: The Sociopolitical Context of Multicultural Education; $c f$. Nieto's The Light in Their Eyes: Creating Multicultural Learning Communities; $c f$. Pepi Leistyna’s Defining and Designing Multiculturalism: One School's System's Efforts). However, it is suggested here that something can be gained when the focus is not just on differences as prescribed by the Contact Zone approach. Multicultural education has become an extensive topic and thus a challenge to even define. Joyce King has warned that many teachers attempting to incorporate multicultural lessons error with "celebrating diversity" drop in lessons that actually reinforce stereotypes (73). Paul Gorski indicates that multicultural education focuses on preparing students to "competently participate in an 
increasingly intercultural society." Thus, "[t]eachers must be prepared to effectively facilitate learning for every individual student, no matter how culturally similar or different" the student is from the teacher (Gorski 1). Gorski's approach to multicultural education focuses on the role of the teacher in recognizing that their students come from diverse backgrounds and have diverse learning styles. According to Gorski, the second phase in multicultural education is that "schools must be active participants in ending oppression of all types, first by ending oppression within their own walls, then by producing socially and critically active and aware students." This accomplishment occurs when education is more "fully student-centered and inclusive of the voices and experiences of the students." These are all appropriate goals to teaching and should be encouraged. Gorski further argues that the goal of multicultural education should be to "affect social change" (2). And this is done by providing educational experiences that lead to "the transformation of self, the transformation of schools and schooling, and the transformation of society" (Ibid.). Sonia Nieto in her text Affirming Diversity: The Sociopolitical Context of Multicultural Education rightly argues that multicultural education "cannot exist in a vacuum" (2). She warns against what she terms the "fairyland" approach where artifacts, food, clothes, and ethnic celebrations are the only focus. For her, multicultural education must be about "Raising the achievement of all students and providing them with an equitable and high-quality education" (Ibid.). This methodology leads to all students becoming "critical and productive members of a democratic society" (Ibid.). In her later text The Light in Their Eyes: Creating Multicultural Learning Communities Nieto indicates that what prompted her to write the book were conversations with teachers about whether or not they should "do" 
multicultural education. It became clear to her that much of what occurs in classrooms in the name of multicultural education was "little more than window dressing" (23). She continued her analysis by stating that the slogan "Celebrating Diversity" which is displayed in many schools nationwide is well-meaning but "glosses over severe structural inequalities that are replicated in schools every day through the combination of uneven access, unfair practices, and harmful beliefs" (50). We can do better.

James Banks and Cherry McGee Banks go so far as to argue in their text Multicultural Education: Issues and Perspectives that if teachers "treat the dominant culture in the curriculum as a matter of cultural borders rather than of boundaries, the classroom can become an unsafe place for students" (53). This, in turn, can invite "student resistance." This approach can lead to schools denying "some groups of students equal educational opportunities" (3). And, as Joyce King has noted, when "celebrating diversity" is just dropped into a unit or lesson this can actually lead to confirming what she terms "dysconscious racism" in students of the dominant group. She defines Dysconscious racism as being "a form of racism that tacitly accepts dominant White norms and privileges" (73). A well thought-out and planned multiculturalist curriculum in this kind of classroom environment can be very beneficial but it must be more than just a day of ethnic foods. Or as Katy Swalweel observes, "for teachers working within homogeneous groups privileged by race and class, providing a critical multicultural education is of tremendous importance. A robust, diverse democracy depends not on self-interested, uncritical kids, but on young people who are willing to step outside of their comfort zones. To do that, students must understand how race and class influence their lives and want to work to make the world a better place" (24). A position that is 
further affirmed by Pepi Leistyna in her text Defining and Designing Multiculturalism: One School's System's Efforts. Leistyna, in critiquing critical multicultural education, laments that "instead of tapping learners as rich sources of information and guidance, the majority of curricula activities within uncritical approaches to multicultural education attempt to affirm diversity by randomly providing such superficial aspects as flag displays, units on particular countries, and food...Although affirming aspects of distant cultures is a step in the right direction...without serious consideration of the existential realities of people here in the United States, multicultural education can accomplish very little" (27).

\section{In Multicultural and Diversity Education: A Reference Handbook Peter} Appelbaum argues that some people believe multicultural education creates a form of "cooperation of minority or disempowered peoples into the system, rather than of challenging white racism" (2). He goes on to indicate that the term "diversity education" may be a better term to use so as to avoid "the increasingly common critiques of multiculturalism that characterize it, regardless of the particular version, as trying to make everyone alike rather than addressing issues of diversity and difference, social inequality, and the need for social change" (Ibid.). In a particularly relevant section of Applebaum's text he suggests that it is the job of "critical diversity educators" to enable themselves and their students to "formulate new languages about differences among people, and about what identities are...because all representation leads to viewing people as 'self' and 'other."' (62). This premise will be dissected and problematized in the analysis portion of this dissertation where an insight will be offered that is based on an Upanishadic theory of being. 


\section{CHAPTER III PEDAGOGICAL INFLUENCES AND METHODOLOGY}

This study explores an alternative approach to the use of writing in a social studies class. Thus, this chapter describes the pedagogical positions employed as well as the data collection methodology utilized while teaching an internship course on NonWest History. Included in this chapter is a section that describes the pedagogical approaches and philosophical influences that informed the construction of this internship course.

\section{Composition Pedagogy}

In the early stages of what would become this dissertation the text Because Writing Matters: Improving Student Writing in Our Schools authored by the National Writing Project and Carl Nagin became a focal point. This text's problematizing of how writing could be incorporated into a course in a way that leads to productive writing assignments that moved away from asking students to produce research papers offered potential for reevaluating writing tasks used in social science courses. Specifically, Nagin $e t$ al. argue that "Subsequent research found that writing could develop higherorder thinking skills: analyzing, synthesizing, evaluating, and interpreting. The very difficulty of writing is its virtue: it requires that students move beyond rote learning and simply reproducing information, facts, dates, and formulae. Students must also learn how to questions their own assumptions and reflect critically on an alternative or opposing 
view-point" (National Writing Project and Nagin 22-23). Writing in a history course could be utilized in a way that would foster creative thought on difficult topics and provide opportunities for students to move beyond rote memorization and repeating what they thought an instructor wanted to hear. Utilizing writing in this way gives the course a different focus, one that would encourage students to re-negotiate Western concepts of being and give students moments to explore alternatives to the dialectical reasoning they so often employ in identity construction.

The writing goal of the internship course became one of creating an environment where the dialectics of Western identity construction could be re-negotiated. This approached blended well with a recent suggestion for writing instructors offered by Kathleen Blake Yancey. She issues a "call to action" where teachers are encouraged to "help our students... become the citizen writers of our country, the citizen writers of our world, and the writers of our future" (1). This suggestion led to the development of an internship course that attempts to create "citizen writers" who could question their own assumptions about existence. Donald Murray suggests that "A great deal of the bad writing we see is the product of bad assignments. Each assignment, after all, stems from the teacher's need to control and a failure to acknowledge that students experience the world, and respond to it, in unique and independent ways" (180). The goal of the internship course became to give students the opportunity to compose texts that led them to an understanding of their relationship with the world, as global citizens. The assignments given are meant to complicate their understandings of the world/other through re-negotiating their understandings of the self as a citizen of that shared world. 
This study also draws heavily from composition researchers Sharlene Kiurara et al. and their investigation into the state of writing in American high schools (published in 2009 in the Journal of Educational Psychology). They find that after surveying how high school teachers around the country utilize writing in their various classes, students "mostly write to convey information or demonstrate their knowledge" (150). Seldom are students asked to use writing "as a means to develop new insights, clarify information, examine personal experiences, stretch the imagination, or persuade others" (Ibid.). Several questions become obvious for a teacher looking to improve a course through better writing assignments: First, what would writing assignments look like that helped students develop insights? Second, how could writing assignments be used to encourage students to stretch out their imaginations in a social science class? Third, how does the course help students, through writing, to develop new insights?

\section{What I Really Value}

In previous sections of this Non-West History course, most of the writing involved requiring students to compose a five paragraph essay on a specific topic. Often times students simply cut and pasted text right from Wikipedia. This methodology changed for the internship. Instead, the pedagogical applications of composition needed to create an environment that encouraged students to use writing to develop new insights and to stretch out their imaginations. In other words, students need to recognize the power of writing to help them think creatively about the world and the self. Whether solving a problem or reflecting on their own existence, writing would become a creative force in this course. Theorizing about assessment became key and Bob Broad's suggestion that "The age of the rubric has passed" (4) would serve as a starting point. 
Brian Huot argues in "Toward a New Theory of Writing Assessment" that "Traditional writing assessment practices are based upon classical test theory..." (549). Rubrics are part of this problem. As Grant Wiggins suggests “Assessments should improve performance...not just audit it" (129). This led Wiggins to observe that "almost all writing assessments I have seen use rubrics that stress compliance with rules about writing as opposed to the real purpose of writing, namely, the power and insight of the words" (132; cf. Broad 10-11). For these reasons the composition pedagogy employed in the internship course would shift away from traditional assessment models based on formulaic rubrics. Broad's suggestion that teachers should not neglect writing that is "Interesting/Lively/Creative" in their construction of assessments of student writing is important (50). This approach to assessment fits well with this study's attempt to move away from writing that was based on rote learning or "research" that could easily be cut from the Internet with not much thinking involved. If students in the internship course were to feel the freedom necessary to stretch out their imaginations, strive for new insights, and write creatively, then assignments given would need to encourage them to create work that is interesting and meaningful to them. This work is documented in a Progressive Measures article (published by the University Assessment Services office at Illinois State University-the co-author is Zach Parton who was a student in the course). The internship course would follow a similar assessment strategy. One that encouraged creativity, not conformity to a rubric.

\section{Pedagogy and Philosophical Influences}

The internship research conducted for this dissertation re-evaluates the use of writing in a high school social science course. This research focuses on the outcomes of 
creating writing assignments that allows for students to be free to strive for creative thought and to take risks in their writing. This calls for a re-evaluation of certain pedagogical approaches overall—much more was involved than changing mentality or altering rubrics. Krishnamurti writes in his classic text Education and the Significance of Life that "Domination or compulsion of any kind is a direct hindrance to freedom and intelligence" (106). To create an environment that is conducive to creativity then students must not live in fear of the instructor. After interviewing Ashok Kurien on the issue of creativity in education, Gottlieb Guntern observes that for the student to achieve creative thought he or she must be in "relaxed mood" (105). Further, Guntern expanded on Kurien's statement that our current state of education "kills children's imagination" (107). This led Guntern to argue that education today creates an "emotional cutting-

off..." (105). He further suggests that "our education systems kill most of these personality traits (open-mindedness, and playfulness)" (Ibid.). The classroom environment needs to change to fit the research methodology employed for the data collection of this dissertation. The following section details the philosophies that led to the creation of the classroom environment.

\section{Carl Rogers, Rollo May, and the Dalai Lama}

Subsequent chapters detail the theoretical lens that shapes the data collection for this study. However, this chapter details the dissertations data collection and pedagogical methodology. This section provides a description of the pedagogical approaches to teaching that are based on the work of Carl Rogers, Rollo May, and the Dalai Lama. 
The reader should keep in mind the above discussion on freedom and creativity when theorizing on the nature of writing assessments as they read over the remarks that follow-they are meant to complement each other.

Carl Rogers once said that "education clings to the past like a leech" (38). And in a very Krishnamurtian statement Rogers observed that the modern educational system was “all based upon a distrust of the student. Don't trust him to follow his own leads; guide him; tell him what to do; tell him what he should think; tell him what he should learn" (36). Rogers argues in his seminal text On Becoming a Person that "if we really value creativity, if we deplore the fact that all of our germinal ideas in atomic physics, in psychology, and in other sciences have been borrowed from Europe, then we may wish to give a trial to ways of facilitating learning which give more promise of freeing the mind" (292). This statement needs unpacking. It is a key point to the pedagogy developed for this internship course. Rogers argues that not only should creativity be the focus of education but that if practitioners only draw from the West then the student's educational experience becomes hindered. This is why utilizing many non-Western thinkers to guide pedagogy can be so productive. Rogers further states, "If we value independence, if we are disturbed by the growing conformity of knowledge, of values, of attitudes, which our present system induces, then we may wish to set up conditions of learning which make for uniqueness, for self-direction, and for self-initiated learning" (Ibid.). Granted, in On Becoming a Person Rogers largely spoke about psychotherapy and its methodology. But in Freedom to Learn he spoke directly to teachers. Here he writes on the importance of what he termed "Empathic Understanding." He remarks that "This attitude of standing in the other's shoes, of viewing the world through the student's eyes, is almost unheard of in 
the classroom" (112). He also indicates that "Independence, creativity, and self-reliance are all facilitated when self-criticism and self-evaluation are basic and evaluation by others is of secondary importance" (163). For Rogers, a teacher has two options. They can focus on helping students realize their potential through freedom and trust or they can focus on controlling behavior through coercion. For the latter students are viewed as deficient and unable to function on their own. For the former, students are autonomous beings in the process of becoming. It is the teacher's roll to guide the student into an authentic being. Thus, teachers must focus on potential and not shortcomings in students (Rogers 117).

Rollo May, a psychologist in the humanist tradition of Carl Rogers, argues in his text Man's Search For Himself that “The struggle to become a person takes place within the person himself" (138). Thus, for a student to learn and "make decisions with responsibility" (139) they must be able to navigate consciousness in a manner that leads to creative "insight." May calls this experience "creative consciousness of self" (Ibid.). During the Non-West internship course, students are challenged to reflect on the self and the other-this approach will be described in more detail in a later chapter on Thomas Merton's influence on the students understanding of the self. May's concept of creative self-consciousness allows the teacher to encourage students to strive for creativity through insight. This can only be done if the teacher realizes that 'Freedom is man's capacity to take a hand in his own development" (160). This logic develops into a key point for teachers because this kind of freedom leads to the development of creative selfconsciousness in the student. For May, this meant "That consciousness of self and freedom go together is shown in the fact that the less self-awareness a person has, the 
more he is unfree...As the person gains more consciousness of self, his range of choice and his freedom proportionately increases" (161-162).

May explored this relationship between freedom and creativity in more detail in his text The Courage to Create. He described what he called the "creative process" as being based on the "encounter" (41). The encounter becomes the basis for the creative act. This internship Non-West History course is developed to give students opportunities to have these kinds of encounters. Specifically, the course attempts to help create an environment where students can encounter ideas that lead to their creative thinking through writing. Texts and assignments are given that encourage students to think about and write about their own ontological constructions_-assignments are not about rote memorization. The course geared the encounter towards student creativity. May argues that we should not speak of a "creative person," but instead of the "creative act" (43). But there can be more than just the encounter. When setting up the course, the readings, texts, films, prompts, etc. the focus was always on the importance of what May calls “intensity" (44). Whether an artist composing, a scientist experimenting, or a child playing; the intensity of the encounter leads to "absorption, being caught up in, wholly involved... By whatever name one calls it, genuine creativity is characterized by an intensity of awareness, a heightened consciousness" (44). Through this approach to teaching the focus shifted to the experiences students would have in the course.

The final pedagogical influence for the teaching of this Non-West internship course derives from a close reading of His Holiness The Dalai Lama. The Dalai Lama's body of work has extensive pedagogical applications, specifically his text Ethics for the New Millennium. 
As the internship course began to take shape the Dalai Lama's argument that we must "cultivate a sense of what I call universal responsibility" became a motivating observation (162). This represents the final piece of this study's approach to teaching in a Non West History course. He suggests that when we neglect others and ignore what he called the "universal dimensions of our actions" (Ibid.) then we fail to see how our interests are bound to the interests of others. This leads us to the dramatically unfortunate situation where "We will overlook the fundamental oneness of the human family" (163). Course need to incorporate these kinds of experiences for the students. The Dalai Lama specifically addresses schools and teachers as he discusses education. He states that "Education is much more than a matter of imparting the knowledge and skills by which narrow goals are achieved. It is also about opening the child's eyes to the needs and rights of others. We must show children that their actions have a universal dimension. And we must somehow find a way to build on their natural feelings of empathy so that they come to have a sense of responsibility toward others" (181). He further remarks that when we educate our children to "have knowledge without compassion..." children will grow up to be envious, suspicious, overly competitive, and have "scorn for those less fortunate" (Ibid.). At this point he addresses teachers directly and indicated that they have a "special responsibility." It is through "positive motivation" that teachers create an environment where creativity and freedom can thrive. He also suggests that teachers should present students with controversial issues and have them "debate" them. This allows teachers to introduce the concept of "resolving conflict[s] non-violently" (184).

This approach to teaching coupled well with the desire to create a relaxed environment where students would engage in creative thought that could lead to deeper 
insight. When the Dalai Lama spoke at Loyola in the spring of 2012 he indicated from the beginning of his remarks that compassion is based on what he called "the common experience." He suggested that our individual survival depends on the community. This is a powerful observation. He warns us not to forget about the basic oneness of humanity. He does not deny that differences exist (religious, racial, social, educational....) but that we place too much emphasis on them. He said, "Same brain. Same emotions." He also indicates that there is too much fear in the world. The source of that fear derives from "distrust of the other." Our emphasis on differences is the problem, he said. By showing compassion toward the other, we actually help the self. His exact words were "Sense of concern for other's well-being is so useful, not only to the other but also to the self."

He specifically addresses the role of teachers and education at several points in his lecture. For example, he indicates that "education about the other must be universal." Education must be based on what he calls "one-heartedness." He was concerned that education in the modern world focuses too much on material things. He also suggests that we could change the world through compassion and that "meaningful peace" could come through education. His last remarks were "World peace through meaningful peace." He then said "Think more, it's good for the young people."

In this chapter a description of the philosophies that shaped the pedagogical views that were employed during the teaching of the internship has been provided. The following section will detail the specific methodology employed in the collecting the data. 


\section{Data Collection Methodology}

The data for this dissertation consists of student writing samples that were collected during the internship Non-West History course offered at a high school in the Midwestern United States. The students are all juniors or seniors in high school. This is an elective course in the social science department. It met five days a week for one hour. Various readings were assigned and several films shown in the course of teaching this class. All writing assignments are collected through Blackboard, an online website that only students enrolled in the class could access. After each reading is assigned a writing prompt is posted in the discussion board of Blackboard where students go to post their written responses. The prompts are given in their entirety in later analysis chapters.

Through these writing exercises the data for this dissertation is collected. Students are prompted to reflect on work by Krishnamurti, Thomas Merton, and Thich Nhat Hanh as well as selections from the Upanishads. Analyzing these student reflections allows for the formulation of the conclusions of this dissertation. Thus, this study is an examination of a personal approach to teaching in light of what and how students in this course learn and do not learn.

The analysis chapters of this dissertation detail student writings in response to specific prompts. Most of the "writing instruction" occurred in one to one conferencing between the instructor and the students. This approach gives students the opportunity to talk about his or her thoughts and writing in a relaxed environment where instructor feedback can enhance the student's understanding of his or her own composings. 
All student names are pseudonyms for the protection of their identities and privacy. 


\section{CHAPTER IV THE UPANISHADS IN THE CLASSROOM}

The previous chapters of this dissertation reviewed the pertinent literature and theories dealing with key pedagogical issues in teaching a Non-West history class in a high school. The remaining chapters focus on the literature and writing activities students undertook in the course. This chapter investigates how students responded to an approach that required them to focus not on the "contact zone" concept of conflict but on the Upanishadic concept of tat tvam asi (you are that- the non-dualist view that the self is the other) and how this assignment aimed at establishing a learning environment that

would help students become the "citizen writers of our world" (Blake Yancey, Writing in the 21 st Century 1). While the previous chapters are meant to provide an academic narrative that outlined the pedagogy employed in this study as well as the specific research methodology, the following discussion analyzes the results of the teaching and learning that occurred in the teaching of this internship course.

\section{The Upanishads Assignment}

For this project, students work in groups of three or four, each investigating a specific Upanishad from the Eknath Easwaran edition (he includes the 10 principle Upanishads: Isha, Katha, Brihadaranyaka, Chandogya, Shvetashvatara, Mundaka, Mandukya, Kena Prashna, Taittiriya, and Aitareya. He also includes four additional 'minor' Upanishads: Tejobindu, Atma, Amritabindu, and Paramahamsa). Students first 
read and discussed the Introduction by Eknath Easwaran and the Afterward by Michael Nagler. The text challenges Western adult readers, so young readers especially benefit from reading these two chapters which contextualize the Upanishads so that Western readers navigate the complexities of Upanishadic style. Students must familiarize themselves with the vocabulary necessary to read the Upanishads and the Introduction outlines several key concepts presented in the broader text. Since several ancient Sanskrit words are the cognates to English words, students begin a study of historical linguistics here. For example various gods and goddesses are discussed in the text, and the Sanskrit for these deities is devas. English speakers will recognize this Sanskrit word as Deva because it is borrowed directly from the Sanskrit. Another example from this specific text is the Sanskrit word for "to know" is vid. This is the cognate for the Latin word video (I see) which is where the English word "video" derives. Students indicate that they are able to relate to the text better after studying some of these vocabulary issues and this enables them to begin to construct meaningful linkages between the ancient texts and their own experiences.

In the Introduction Easwaran suggests that when reading the Upanishads students need to be aware that the textual purpose of the authors appears to be "not so much instruction as inspiration" (20). Students are used to being "instructed." This distinction created a moment in the course where pedagogical boundaries were engaged. At this point students need to re-think their relationship with the instructor and their own abilities to construct knowledge based on their own understandings which they derive from the text and blended through the lens of their own experiences. The project challenges students to negotiate their understandings of "instruction" and "inspiration." Their job 
when doing their presentation is not to "instruct" the class. Their presentations must engage their peers through an ability to inspire. They are usually puzzled and begin asking questions about how they can do a presentation that is not about showing what they know on the assigned topic. We then talk about the possibilities available for them to utilize when they present--such as art, music, leading us in meditation, dance. The important thing is that they feel freedom. Many students fall back on using powerpoint. If they wanted to compose some poetry or create a piece of art that explored their Upanishad that is an acceptable approach. Then, inevitably, someone asks "How many points is this worth?" This created a wonderful Upanishadic moment because they are then informed that it is not possible for a grade to be given for this project. This confuses many students. They "elected" to take this class because they want to do the work. Thus, the assumption is that they will do it. Secondly, how can the instructor "grade" a project that is all about inspiration and creative thought? In this project, the students have the power. Not the teacher. Once the stress of the grade is removed, they begin to experience the freedom in which Upanishadic ontology derives.

In the Introduction Easwaran also explores the idea that the authors of the Upanishads view the "mind" as one of the senses—along with sight, hearing, taste, feeling, and smelling. The mind is the sixth sense in Upanishad epistemology. While addressing this concept during the discussion of the Introduction, it is informative to ask students what Easwaran means when he wrote that the Upanishad sages concentrated on consciousness itself by asking the question "Who is the knower?" (25). Students commonly respond to that question: "I am the knower..." Students are then pointed to the follow up observation Easwaran made when he stated, "But gradually you become 
aware of the presence of something vast, intimately your own but not at all the finite, limited self you had been calling 'I"' (37). He further argues that "All that divides us from the sea of infinite consciousness at this point is a thin envelope of personal identity. That envelope cannot be removed by any amount of will; the 'I' cannot erase itself. Yet, abruptly, it does vanish. In the climax of meditation the barrier of individuality disappears, dissolving in a sea of pure, undifferentiated awareness" (37). For the student of the Upanishads this provides the key experience: Liberation (moksha). This produces a state that brings freedom "from all conditioning..." (38). And while this creates a serious moment in Hinduism and takes years of study and meditation the point is made to the students that this "freedom from conditioning" becomes the basis for the pedagogical outcomes of the Non-West History course.

This epistemological direction helps students navigate the possibilities involved in an educational space that motivates the students to understand that explanations are not enough when constructing knowledge. Explanations exist as part of the illusion. And as Easwaran argues, the everyday world ontologically cannot be the illusion, "The illusion is simply that we appear separate; the underlying reality is that all of life is one" (44). When students think about this concept and discuss it they usually express confusion. When asked if they think their confusion derives from their "conditioning," a pedagogical moment takes shape where they can begin to understand this basic Upanishadic construction. That culture, religion, education, anything they can come up with....has conditioned the way they think and experience the world. What happens, if that conditioning is altered? This question creates a moment where students gain the 
opportunity to overcome the constructed nature of their own understanding. Students then read through the Afterward of the text by Michael Nagler.

Before students are assigned a specific Upanishad to study in depth they are directed to read and analyze the Afterward. In this brief chapter Michael Nagler outlines the significance of the Upanishads for the modern reader (or as Sri Chinmoy would call a student of the Upanishads, a "seeker" [40]). Nagler makes the point that even though the textual construction becomes "wrapped in a good bit of mythology and ritual, that wrapping comes off pretty easily" (296). To illustrate this Nagler quotes extensively from people who have applied the teachings of the Upanishads in their work. He refers to Arthur Schopenhauer's ethics which were so infused with tat tvam asi (Schopenhauer once said that the only book he kept on his nightstand was the Upanishads). Nagler cites Rabindranath Tagore (the first South Asian to win a Nobel Prize for literature) and his focus on the history and importance of asceticism in Indian thought. Most students possess some familiarity with Mahatma Gandhi and Nagler has multiple references to how Gandhi thought about the Upanishads—-such as Gandhi's use of the phrase "renounce and enjoy" from the Isha Upanishad. But perhaps more importantly for this argument is Gandhi's point that there must be "heart unity." Which Nagler indicates was Gandhi's way of promoting "Unity in diversity" (329). This chapter helps prepare students for reading their assigned Upanishad. It aids them in developing the necessary critical reading skills necessary to identify important Upanishadic concepts (such as tat tvam asi; or moksha). Readers are encouraged to search for the teacher and the student in the text, as well as the metaphorical nature of the mythic beings that often appear in the Upanishads. Thus, students became better prepared for the rather cryptic nature of the 
narrative. They understand that in reading their assigned text they must experience it differently than most things they have read in the past.

\section{The Project}

For this project, students are broken into groups of 3-4 and assign each group a specific Upanishad. Some are more lengthy than others and some more difficult to process than others (usually this is because some are filled with Sanskrit terminology and some are not). Students are directed to prepare a presentation on their assigned text and in keeping with the Upanishadic tradition of a teacher giving a student an experience; students are asked to think of themselves as the teacher. However, they are instructed to not simply "teach" the Upanishad to the class, but rather give the class an experience of the Upanishad. This is why they are encouraged to create a unique experience for their peers. Below is the specific set of directions that are given to the students:

After studying your Upanishad, in your group come up with a way to give the class an experience that allows them a deeper understanding of the text. Please try to convey as many of the following items as your Upanishad allows.

1. What is the title, setting, and theme of your assigned Upanishad?

2. Who are the principle characters?

3. What is the message of the text?

4. What does the Upanishad assigned say about "the self?" What does it say about "the other?" 
5. Does the message/meaning of the Upanishad apply philosophically to today? Here? Now? In what way?

6. Give one excerpt your group thinks is the most meaningful for us to discuss as a class.

7. Explain what your group found to be the most philosophically insightful meaning derived from your reading of the Upanishad.

8. What does your group wonder about after reading your assigned Upanishad? Where did it take your thoughts about existence?

9. How does this Upanishad help us understand Tat tvam asi? You are that.

10. Your presentation should be a conversation. You are the teachers here (remember the Sanskrit word Upanishad means "to sit down next to"). You can utilize any method you see fit but make it creative. Make us think. Remember, the ancient authors of these texts viewed the "mind" as one of the senses, along with sight, sound, vision, touch, smell... Try to take our minds into a deeper level of consciousness through this conversation. [After we completed the group presentations one of the students pointed out the error of this assignment. She indicated that since, according to the Upanishads, we could not "think" our way into understanding, the requirement that the presentations "make us think" was very un-Upanishadic. Brilliant.].

As part of this overall project students not only conduct a group presentation but they also post a discussion board response as an individual. In their online post students 
are asked to reflect on their Upanishad and write about the experience of studying it from the perspective of "you are that." Tat tvam asi.

\section{Analysis}

Many of the presentations are typical (they often consisted of power point slides with bulleted text that listed out characters—although some students are creative, composing music or painting a piece of artwork). However, the reflective online writings students produce interesting results. There is anonymity in an online discussion board that allows students to communicate views without having to stand up in front of their peers. Jill, who studied the Brihadaranyaka Upanishad, indicated that the ultimate message was that we should "be compassionate because the Self in us recognizes the Self in others....So the Self is not these things it is the same in all of us." This student made this clear in her group's presentation as well. True, this Upanishad is about compassion and her final analysis is similar to Easwaran's suggestion that this Upanishad is teaches that the Self "which is identical in all of us..." is the basis of life (95-96). This is a difficult text to read with multiple characters and multiple sub chapters.

Marian wrote about the Prashna Upanishad observed that it was really about a teacher instructing students "who seek the Self through positive ways such as Selfdiscipline, wisdom, and meditation..." will be able to achieve enlightenment. This student in her presentation attempts to show that the text argues that the Self is pure consciousness. This student attempts to grasp what the text is arguing and she offers a simplistic retelling of the Upanishad. However, her approach encourages thinking about how the "quest for wisdom" is really the beginning of Self-realization. This student 
focuses her response on the development of wisdom in the search for the self. In studying her response it became clear that the overall project neglected this process of wisdom development.

Death teaches the main lessons in the Katha Upanishad. This presentation and online follow up writing allows these group members to outline not only their interpretations of a difficult text but also allows them to talk about ways that they conduct additional research and came to their conclusions. Amy, a student in this group, indicated that at first she is troubled that Death is a character but then she began to see things differently. She writes that the text wasn't "necessarily the dark, gloomy stuff I was expecting." At first she is locked into her own perspective about death/Death. She neglects the aspect of Hinduism that indicates that there is transmigration of the soul...giving a very different perspective on death to the original readers of this text. However, during the presentation the group focuses on one of the important lessons that Death teaches. That "Far apart are wisdom and ignorance. The first leads one to Selfrealization; the second makes one more and more estranged from one's real Self..." These students conclude that the ultimate message of the Katha Upanishad is one of "hope." This is very different from what they thought when it was originally assigned. This is one of the lessons learned on many occasions teaching this unit. This text challenges some basic cultural conventions that some people tend to cling to (i.e. Death is bad...). There are many possible lessons learned from the Katha Upanishad but this group focused on "hope." They recognize that "Death" as a teacher could be a positive force for the development of wisdom that leads to hope. This resonates with them. Many of the students in this course look forward to graduating high school and moving out into 
the broader world. For many of them this leads to anxiety and fear as well as the hopeful feelings so common in youth. In assigning this group this text the class as a whole is given an opportunity to examine how an ancient text impacts one possible way they can reflect on their own future. .

The Kena Upanishad offers a more detailed examination of consciousness and the self. Students tend to struggle with this text. The students working with this text conclude that the text largely explores "what the self is." This is not a bad interpretation, just limited. In fact, they recognized that they did not understand this text and during the presentation made the comment that it is difficult because "we are used to always having an answer for what something is..." Students like defined answers. Brad, a member of this group, wrote in the discussion board that the thing that bothered him is that the text defied interpretation. It troubles him that the text seems to suggest that "in order to find the self you must first realize that you don't know the self and can never understand the self..." This insight is interesting because the student restates the Upanishadic text ("That which makes the mind to think but cannot be thought by the mind, that is the Self indeed" [214]) in a rather Western (i.e. Socratic) stylized sentence. Olivia, another member of this group, has similar struggles with interpretation. She suggests in her writing that according to the Upanishad "the Self is the Other." Taking it deeper she goes on to explain that "Everything is the same and the Other should be treated as the self. This helps us understand Tat Tvam Asi, because it shows that You (Self) are That (Other)." This is a problematic statement because the text does not argue that "everything is the same." However, she tried to understand statements in the text like "See the Self in all, and go beyond death," but found it difficult (215). She picked up on 
a partial understanding and then made a conceptual leap that is natural for someone trying to work out the meaning of this Upanishad. This student's response illustrates the complexities of teaching texts from Non-Western philosophies to American high school students. This student's response was shaped by comments others made in class. Thus, she argues that "everything is the same" and left it at that. This response shows how difficult it can be for students to digest the notion of non-dualism and filter it through their own cultural and philosophical lens, which can be seen in this student's response. As Raimundo Panikkar argues, monism (i.e. "everything is the same") is a misunderstanding of reality based on illusion (maya). He suggests that the non-dualistic nature of an Upanishadic approach to understanding existence "makes room for pluralism, not as competitor of the One, but as enhancement of effective oneness" (657). In subsequent semesters changes have been made in pedagogy to redirect student thinking on this Upanishad in an attempt to engage the concept of "unity in diversity" in a manner that helps them think about this Upanishad in a way that leads to an interpretation in the spirit of non-duality with a basis on unity through diversity as opposed to an unchecked egoism that concludes "everything is the same." Following the Upanishadic logic of Advaita Vedanta allows the teacher to create a multicultural course that can promote tolerance and an appreciation for diversity in a way that empowers students who self-identify with a minority group. However, this approach can also bring about a serious empathic awareness in students which change their perceptions of how they exist. The outcome of this unit supports the theory that student perceptions can change in a way that leads to empathic awareness that the self is more than the individual. Here Lakoff and Johnson's theory that "New metaphors have the power to create a new reality" (145) 
seems to be occurring. Students seem willing to recognize that their "conceptual system" (Ibid.) is changing based on how their perceptions of the world are changing based on this unit of study.

One of the things that students are asked to keep in mind at the beginning of this unit (which occurs early in the semester) is the Upanishadic concept of tat tvam asi. Their presentations on the Upanishads as well as their reflective writing illustrates that these are difficult texts for high school students. These texts open the door to students reading, talking, and writing about issues that are important in a course promoting multicultural communion (more on this in the Thomas Merton Thich Nhat Hanh chapter). The reader of this dissertation no doubt notices that the conversation is not about "grappling" with diversity in the "contact zone." The nature of the prompts students reflected on and the instructions for the presentations are focused on respect for the potentially unifying properties of the Upanishads and a philosophy grounded in recognizing the self in the other. This will be built on this in the next chapter when student writing in response to J. Krishnamurti is analyzed. One of the overall lessons that teaching this unit taught me was that the rhetoric employed when encouraging students to develop creative insights about the self and the other based on Upanishadic epistemology comes down to them developing a clear understanding of the difference between tat tvam asi (you are that) and conclusions that the Upanishads teach that "everything is the same." This requires complex thinking that defies the ways that Western students typically categorize their existence. Yet, even with a serious attention to these texts, most students never made the conceptual leap into non-dualism. Their Western concepts of identity and existence frustrated them as they struggled through the texts. Lakoff and 
Johnson outline this issue when they argue that when a person begins to understand their existence in terms of new metaphors discovered, "cultural change arises from the introduction of new metaphorical concepts and the loss of old ones" (145). Thus, students could not move past the idea that "everything is the same." This is a very different ontology than "you are that." Tat tvam asi embraces the concept of unity in diversity as a way to ethical non-dualism. Some students seem to be trapped by their metaphors. Rhetoric such as "everything is the same" implies that diversity does not exist - a rather un-Upanishadic conclusion. This inability to fully understand the Upanishads as a liberating text steeped in the promotion of unity through diversity became a major source of frustration. In future semesters this conflict will need to be examined more meaningfully with students.

Kathleen Blake Yancey wrote in her essay "Made Not Only in Words: Composition in a New Key" that one of the challenges to creating a "post-process compositional curriculum" requires teachers to rethink and question the "late-20th century basis of composition" (309). She argues that teachers need to reformulate the way composition is taught in the school context. The question becomes what is best for students when theorizing on composition in the 21 st century? She suggests that the way teachers approach composition needs to change because the traditional school context (essay tests for example) stands in direct "contrast to the world context" (309; emphasis in the original). For Blake Yancey the biggest problem derives from the fact that composition pedagogy "embodies the narrow and the singular in its emphasis on a primary and single human relationship; the writer in relation to the teacher" (309). She concludes her paper with a plea that since composition teachers should be helping to 
create a writing public, they must also foster citizenship. But she takes it further; she is not just referring to basic civic responsibilities. Blake Yancey envisions composition teachers who help create "citizens whose civic literacy is global in its sensibility and its communicative potential, and shows commitment to humanity that is characterized by consistency and generosity as well as the ability to write for purposes that are unconstrained and audiences that are nearly unlimited" (321). Blake Yancey updates this call in 2009 when she published "Writing in the 21st Century" in which she asked teachers to revise their composition pedagogies in ways that would "help our students compose often, compose well, and through these composings, become the citizen writers of our country, the citizen writers of our world, and the writers of our future" (1). This Upanishad assignment occurs early in the semester and is the pedagogical foundation for the approach to the course. By researching, talking, and writing about a specific Upanishad students have an experience with a core text in South Asian philosophy that is radically different from anything most of them have ever experienced. As $\mathrm{S}$. Radhakrishnan and Charles Moore have suggests, it is a philosophy inherently introspective in its approach to reality and can lead one to gain an understanding that when one studies the inner nature of the self they gain an understanding of "man universal" (xxiv-xxx). This unit serves as a stepping stone in a pedagogy geared towards Blake Yancey's call for our students to become the citizen writers of the world. To begin this process, students must develop an empathic awareness of the world and their place in it.

This dissertation argues that if composition is to actively engage students in ways that allow them to navigate Blake Yancey's call for students to become the citizen writers 
of the world, they must re-evaluate the nature of the constructed self in the world. This Upanishadic project helps to create this kind of citizen writer. As Sri Chinmoy once suggests at a speech at Cornell University, the basic question for the "self-enquiry" driven student of the Upanishads is "Who am I?" (94). To which the Upanishadic answer is "Tat tvam asi. "That thou art"” (Ibid.). This observation is remarkably similar to one made by composition theorist Derrick Jensen when he suggests in his text Walking on Water: Reading, Writing, and Revolution that "There is really only one question in life...The question: Who are you?" (41). The writing assignment described in this chapter provides a starting point for students to begin the journey of negotiating the boundaries of the self and the other. For students in this Non-West History course, the Upanishads serve as the starting point for them to have the opportunity to become citizen writers of the world. 


\section{CHAPTER V \\ J. KRISHNAMURTI IN THE CLASSROOM}

Arthur Schopenhauer argued in 1839 that compassion should be the basis for all morality (On the Basis of Morality 183). He later elaborates on this suggestion in one of his essays on Ethics. He argues that the foundation for his concept of morality is found in the Upanishadic concept of tat tvam asi. He elaborates by saying that "The recognition of one's own essential being in another" is the reason why people will act selflessly to save someone in trouble. Because in that moment they understand that they are the other. It is in these moments that we subconsciously understand the need for defragmenting our lives. After the students studied the Upanishads to gain an understanding of tat tvam asi (you are that) the next unit of study directs their attention to the work of J. Krishnamurti. This chapter outlines the two key Krishnamurti texts that students read in this unit and then provides an analysis of student writing based on a specific prompt. The chapter concludes with a theoretical comparison of student writing and the arguments emerging from current brain research on mirror neurons. The analysis section of this chapter provides a discussion of the activities and texts students engaged in the unit. This section focuses on the practical aspects of teaching Krishnamurti to high school students and the pedagogical methods employed. The final section of the chapter critically explores the pedagogy employed through the lens of rhetorical theory as it relates to recent trends in brain research. This section is designed to challenge composition theorists to rethink the 
role of writing in creating opportunities for students to gain skills that led to the development of empathic awareness.

The nature of Krishnamurti's work makes it difficult to classify. Many of his texts are shelved in the Eastern philosophy section of the library. However, many publishers label these texts topically as "Religion." G. Vedaparayana describes Krishnamurti as someone who "examines the mind and life, not as a professional philosopher or as a psychologist or as a neurologist but as a common man who is seriously concerned about the crisis in the mind and the world" (548). This description would suit Krishnamurti no doubt because he did not consider himself anything other than a man who liked to discuss truth. He took a stand against labels and consistently argued for no methodology, religion, or ideology. In fact, these became the very things that one had to overcome to be free. After the students studied the Upanishads and the concept of tat tvam asi, this unit of study directed them to read several texts by Krishnamurti that expand on the suggestion that we live a non-dual existence. Krishnamurti maintains that the only way to truly understand our selves requires the recognition that our lives are conditioned and that we are essentially fragmented. As Krishnamurti wrote in Freedom from the Known, that our "conditioned mind" obstructs our ability to understand that we lead fragmented lives. Until we defragment, we will never overcome what he calls "the corridor of duality" (114).

The Upanishad concept of tat tvam asi (you are that) set the epistemological foundation for an approach in this course and Krishnamurti challenges students to understand that they experience the world in a deeply conditioned way. Students are assigned two texts to read by J. Krishnamurti. The first text comes from his book The 
First and Last Freedom. They are assigned a chapter titled "Awareness." Here he outlines his idea that to know oneself means to know oneself's "relationship with the world" (94). For him, life is "relationship to the whole" (Ibid.). In this essay Krishnamurti asks the question "what does it mean to be aware?" For Krishnamurti, a person becomes aware when he or she can see the whole process of their thinking. Students become troubled by his observation that when a person condemns something, that condemnation exists because he or she doesn't understand the thing under consideration. This becomes the modus operandi for most of us according to Krishnamurti's theory because once we condemn something we now can avoid trying to understand it. Yet, life exists as a problem of relationship. If we can become aware of what he calls our "inward nature" then we can begin to search out answers to the problem of relationship recognizing that we live lives conditioned by our prejudices, demands, pursuits, etc. This becomes the first step towards release. He concludes by suggesting that "life is a matter of relationship; and to understand that relationship, which is not static, there must be an awareness which is pliable..." (98). He tells the reader that awareness cannot come through "any form of discipline, through any practice." (Ibid.). In other words, nothing that conditions the mind. Krishnamurti defies the "religious thinker" label because he rejects religion (and religious texts) as a method of understanding...including the Upanishads.

Students then read Krishnamurti's article titled "A Relationship with the World." In this text he develops his non-dualist theory that "The world is you and me, the world is not separate from you and me" (Total Freedom 289). He argues that unless a person understands (and has awareness) of the global, "universal, sense of the whole human 
being, you will live merely in fragments..." (Ibid.). The main issue in this essay becomes that of relationship. If we don't understand that we must look into ourselves in order to understand "the whole of human existence" then we will never understand how relationship conditions us. Part of the overall problem is "thought." Through thought, we create a notion that beings exist as a "me" and a "you." This creates fragmentation because thought divides us. And unfortunately this outcome occurs because of the nature of our educational experiences. Krishnamurti explained that "We are educated to conform to the division of the observer and the observed..." (299). He further claimed that we divide the universe as the "me" and the "you." Thus, people lack the ability to understand the world. We particularize. The "me" creates a fiction (304). Once a person understands and develops awareness that the "me" is based on relationship, they can then begin to understand how this conditioning operates. This understanding of being becomes the first step in gaining awareness that the "me" is the "you."

This chapter argues that Krishnamurti's work helps students as they begin exploring the concept of empathic awareness. New evidence emerging from contemporary brain research now seems to confirm what Krishnamurti argued (this will be discussed in a later section of this chapter). And if we, as writing teachers, apply his suggestions to our pedagogy—specifically that we can become defragmented through an awareness of our conditioning, then students can begin to develop an understanding of the Upanishadic concept of tat tvam asi in relation to empathy.

After students read the assigned texts the next stage of the unit directed them to reflect on the following prompt in an online blackboard discussion post. They do this prior to our discussing the material as a class. 


\section{The Prompt}

Students are assigned the following prompt:

Krishnamurti states in his chapter on "Awareness" that "To know ourselves means to know our relationship with the world..." He then goes on to say that our problem is "always a problem of relationships..." In this discussion board post indicate what you think about his suggestions. Use quotes from the readings, use examples from your life experiences, use the Internet, and use your conscious thoughts.... I want to know what you think about his views.

Then look at his essay called "A Relationship with the World." Explain how you think his concept of awareness blends with his statement that the "disintegrating world is your mind." He also argues that "fragmentation" is brought about by the "me" and the "not me" in our thought. Explain how this relates to the Upanishad concept of "Thou art that." What would happen if you started viewing others (the "not me") as if they were you (the "me")? Brainstorm the implications of Krishnamurti's theory.

\section{Analysis}

Analyzing student writing on the Krishnamurti prompt provides insight into their understanding of empathic awareness. This unit is designed to move them out of their comfort zone. As this dissertation argues, asking students in a Non-West History course to read writings from Non-West authors greatly enhances their experience in the course. This should be part of the curriculum. Many of the students find Krishnamurti's position on "fragmentation" an accurate description of the problems faced in the world. Mary indicates that she understands Krishnamurti's idea of the "me" and the "not me" to be a 
helpful way for her to think of her relationships with the "other" as "part of ourselves." She suggests that she could see how this view would lead to "compassion and empathy." Interestingly, Steve agrees with Krishnamurti's point that all of our problems stem from relationships, but he disagrees that fragmentation is a problem in the world today. He cannot accept (like the previously-cited student) that "we are all the same" which became the way he interpreted Krishnamurti argument. Yet, he concludes his essay by stating that if we focus on fragmentation this might lead to a judgmental view of others where we "judge people based on their likes and interests." For him this would be a serious problem. Krishnamurti does not suggest that "we are all the same" in the essentialist (surface) way that this student perceived and it never becomes clear where he picked up the idea that if we accept that fragmentation exists as a problem that must be overcome, then this would lead to a belief that "we are all the same." This student's response illustrates the complexity of Krishnamurti's argument.

Kate responds to the prompt by connecting Krishnamurti's concept of seeing the self as the other to the Confucian concept of ren (roughly translated as humanness). She blends the concept of ren with Krishnamurti's concept of relationship. She suggests that "we should see our-selves in 'the other' and only then can the relationship prosper." This student links two difficult Eastern philosophical concepts in her post. Her response also echoes much of what has come out of the neuroscience literature on empathy ( $c f$. Marco Iacomboni's observation that mirror neurons "make the other 'another self,", Mirroring People 147). Many philosophers (and historians) might argue that she inaccurately equated Krishnamurti to Confucius, but it is argued here that by thinking about the Krishnamurti text she fell back on prior knowledge to link the two philosophies in an 
interesting way. Krishnamurti is not linked to Confucius in the literature. Thus, her insight became even more impressive. Some historians or philosophers might challenge it for accuracy, but this insight illustrates creativity not usually found in high school student.

Ellen takes the argument in a direction where she indicates that goodwill and safety could result if "we were to stop thinking of 'others' as 'not me' but instead as 'me.' She suggests in her essay that this shift in thinking could lead to the recognition that our "choices and actions" have a direct impact on other people's lives. She recognizes how Krishnamurti's insights can impact our own safety. Krishnamurti never refers to accepting his theory as a way to promote "safety." However, it shows an application to how Krishnamurti's writing can impact a teenager living in today's world. A very different world than the one Krishnamurti lived in. Another striking aspect of this student's writing was how her answer to the prompt echoed the Hindu concept of Karma - the idea that actions have consequences beyond the individual self. The eight fold path of Buddhism reflects this philosophy as well. Specifically the path known as right action (samyak karmanta; $c f$. Radhakrishnan and Moore 277-278). She doesn't mention these things but these ideas were covered in class and these concepts color her writing. She subconsciously fell back on prior knowledge when writing her response.

Rosie saw that Krishnamurti's concept of relationship extends beyond people. She notices that he promotes an approach to relationship that incorporates all aspects of being (people, animals, the environment, etc.). She understands that "we must start looking at them [the not me] as an equally important unit in our ability to function." This concept of being did not develop fully in Western philosophic circles where humans 
and animals do not exist on the same plain of importance. Her thinking follows the logic found in the novel Ishmael by Daniel Quinn where the gorilla narrator tells his student that in regards to the natural world some humans are takers and some are givers. Or, as Marc Ian Barasch states in his text Field Notes on the Compassionate Life: A Search for the Soul of Kindness "Perhaps our ultimate human assignment is to extend our sense of kinship beyond family and clan and strangers to all other creatures" (309).

Some students frame Krishnamurti's concept of relationship to that of a "connection." For students today the technology they utilize to build relationships often fosters a false sense of belonging or being "connected" to others. Clinton couldn't escape the allure that Krishnamurti argued that we all "need to be connected." Unfortunately he did not elaborate on how he was defining "connected" and he comes off as being too simplistic (and possibly focused on the technology of connecting). Interestingly, Krishnamurti writes in Education and the Significance of Life that while "technological knowledge" was necessary, it will not help us solve problems and conflicts. Instead, he warns that "because we have acquired technical knowledge without understanding the total process of life that technology has become a means of destroying ourselves" (19). This student does not share this view. Further, his essay is rather brief (one paragraph) and he did not develop his ideas as fully as possible. When called on during the class discussion of the texts he stated that "we all need to be good" because this impacts the other in ways that we might not understand.

Every teacher enjoys that moment when a student gets excited in class about a particular topic. This happened with one student who seems to turn Krishnamurti's theory upside down. Normally Krishnamurti focuses on the need for self-awareness and 
understanding as a way to understand the other. Claire switches this around and stated "I think our interactions with others are what help us to become our-selves." She indicates that "after reading his [Krishnamurti's] piece on awareness...I take away from this piece, that we must search past what we think we have found...To have awareness is to understand your relationships and I think Krishnamurti suggests that relationships don't really matter because you must focus on your relationship with your mind before you can try to even understand any of your other relationships with the world." This remarkable insight into Krishnamurti's concept of relationship shows creativity. She then writes "Fragmentation...is the dividing of pretty much everything. Separating oneself as the 'us' and the other as 'them."' She concludes her writing arguing that "if only I were to view the 'other' as 'myself.' I think I would be a lot more compassionate." This observation illustrates the importance of assigning students texts that promote compassion in the place of conflict. Her response shows that she approaches the texts seriously yet cautiously enough to be open to their meaning. Through her analysis of Krishnamurti's thesis this student recognizes that change was possible but only after contemplation on how fragmentation controls the way we understand our lives.

Several students made comments in class stating that they simply had no idea what Krishnamurti is talking about. However, most students possess a willingness to try to understand these texts and many seem excited to read something that is so different than what they normally read in school. To read Krishnamurti after a study of the Upanishads allows students to begin to process the idea of non-duality. This can be seen from the writing excerpts where many students began making the conceptual leap necessary when it came to understanding the other in light of the self. This approach 
leads students to a deeper sense of empathy and compassion. These texts prove to be a good starting point to take students in a Non-West History class more critically and creatively into an experience where they could freely explore their place in a multicultural world. In both the Upanishad chapter and this one on Krishnamurti, we can see students beginning to recognize, not the conflictive existence of the contact zone approach but instead a direction that allows them to understand the self in an empathic relationship with the other. Krishnamurti wrote in his text Education and the Significance of Life that the role of the teacher must not condition the child to be a cog in a machine, but instead to help students become an "integrated, creative human being..." (102). With this unit, students obtain the cognitive tools to realize the potential of this epistemological and pedagogical positioning. Through this positioning, students find themselves better equipped to develop skills necessary to negotiate the non-dualist nature of existence as outlined in this study.

\section{Pedagogical Implications and Brain Research}

As indicated earlier in this chapter, Krishnamurti's texts are difficult for students educated in the West to comprehend. It is further suggested that Krishnamurti is a good place to explore the concept of empathic awareness. Following this observation, this dissertation additionally argues that brain research now confirms much of what Krishnamurti argues. The review of the literature on mirror neurons (as well as what is now termed "neurorhetoric" $c f$. Mays and Jung pp. 52-55) earlier in this dissertation illustrates this conclusion. One of the things the researcher learned from students during this unit was how their responses to Krishnamurti often reflected how brain researchers (especially in regards to mirror neurons) write about emerging findings about the brain. 
Jeremy Rifkin, an economist and an historian, frames his text The Empathic Civilization:

The Race to Global Consciousness in a World in Crisis (which is sweeping interpretation of world history) through the lens of brain research's emerging insights into empathic awareness. He suggests that "Because empathic skills emphasize a non-judgmental orientation and tolerance of other perspectives, they accustom young people to think in terms of layers of complexity and force them to live within the context of ambiguous realities where there are no simple formulas or answers, but only a constant search for shared meanings and common understandings" (15-16). Or as Christian Keysers argues, "It is heartening to realize that there is something inside us that makes us truly care about other individuals as if they were part of our extended self" (24). Studying the Upanishads alongside of Krishnamurti creates these moments where students can develop what Lakoff and Johnson term the "metaphorical imagination" (231, cf. Gallese and Lakoff's text “The Brain's Concepts: The Role of the Sensory-Motor System in Conceptual Knowledge" published in 2005).

When reading over student writings about Krishnamurti and his views on fragmentation, the self and the other, and conditioning one can see that while they struggle with the texts, many of them began to develop openness to his argument. When he suggests that the reason problems persist in the world is not because of the world, "The creator of these problems, is the individual, you and I...the world is your relationship with another. The World is not something separate from you and me...to understand the world we must understand ourselves. The world is not separate from us; we are the world, and our problems are the world's problems" (First and Last Freedom 42). Or, as George Lakoff argues, we need to develop a "new consciousness, a basic 
stance toward each other and the world. It requires the realization that empathy and responsibility are at the heart of the moral vision..." (117; $c f$. Lakoff and Johnson 115). The above discussion also analyzes student work and suggests that there are links to how students theorize about Krishnamurti's views and theories now developed by contemporary brain researchers. In their responses many students echo Marco Iacoboni (This is significant because students never read any of Iacoboni-or any other neuroscientist's - texts, they came to these conclusions on their own).

Marco Iacoboni pioneered mirror neuron research. In his book Mirroring People: The Science of Empathy and How We Connect with Others published in 2008 but detailing his research on the brain going back to the early 1990s, he makes many statements that relate to observations students cited in this dissertation make about the self and the other. Jeremy Rifkin also cites Iacoboni extensively as well. Iacoboni poses an interesting question in a chapter titled "Facing Yourself." He asked, "How can we even think of 'self' except in terms of the 'other' that the self is not? Without self, it makes little sense to define an other, and without that other, it does not make a lot of sense to define the self" (133). He answers that question by suggesting that mirror neurons generate the "neural glue between self and other..." (Ibid.). He further states that "Mirror neurons link profoundly self and other. I would even argue that the self and other are blended in mirror neurons..." (152; emphasis mine). He concludes his book suggesting that current brain research shows that "We have evolved to connect deeply with other human beings. Our awareness of the fact can and should bring us even closer to one another" (272). Or consider Christian Keysers comment in his review essay “Mirror Neurons: Are We Ethical By Nature," he states, “These brain circuits [mirror 
neurons] can keep us from seeing other individuals as something 'out there.' Indeed, we are able to feel their actions, sensations, and emotions inside us, as if we were in their shoes. Others have become us" (20; emphasis mine). Writing in the Annals of the New York Academy of Sciences, Jean Decety argues in an essay titled "The Neuroevolution of Empathy" that while the term "empathy" is shrouded in "conceptual diversity" (35) research shows that when theorizing about the nature of mirror neurons there is a "blurring [of] the line between self and other" (Ibid.). And while one should be aware of Jack and Appelbaum's warning that teachers must "be wary of weak analogies that seek to offer scientific proof of the effectiveness of any given pedagogical method" (428), or Mays and Jung's cautionary comment that "mirror neurons guarantee nothing" (53), this chapter argues that these students have shown that through reading the work of Krishnamurti on fragmentation, conditioning, and the self and the other, they drew similar conclusions to brain scientist looking at fMRI results. This examination illustrates that students, given texts that challenge their conceptual framework on existence can formulate complex understandings of empathic awareness based on new metaphors of understanding as Lakoff and Johnson hypothesize as well (for a critical analysis of Lakoff and Johnson's experientialist theory of new metaphor see Steven Pinker's text the Stuff of Thought: Language as a Window Into Human Nature pp. 245261) 


\section{CHAPTER VI}

\section{THICH NHAT HANH AND THOMAS MERTON IN THE CLASSROOM}

After introducing the students to the Upanishads and the concept of tat tvam asi, and assigning them texts that challenge them to apply the Upanishadic concept of nonduality to Krishnamurti's assertion that we lead divided lives based on fragmentation and conditioning the next unit introduces students to Buddhism through the lens of Thich Nhat Hanh. This unit complicates their thinking about what Nhat Hanh argues by blending his text on "Understanding the Buddha's Teachings" (which appears as a chapter in his book The Heart of Buddha's Teaching) with an excerpt from Trappist monk Thomas Merton titled "Between East and West." This chapter begins by exploring the theories of being expressed by Thich Nhat Hahn and then provides a critical analysis of student work. The second part of this chapter reviews the assigned Thomas Merton text and then provides a critical analysis of student responses to his theory of "communion." The chapter concludes with a discussion of how the results link with composition pedagogical goals. Teacher practitioners interested in replicating the assignment and retheorizing their pedagogical methodologies may find the analysis of student work useful. Composition theorists interested in how non-Western texts can be blended with Western concepts and how the pedagogical strategy Merton called "communion" can impact composition theory in a course designed to challenge students to re-negotiate their identity based on multicultural understandings may find the final section of this chapter meaningful. 


\section{Thich Nhat Hanh}

Following up Krishnamurti with Nhat Hanh's text challenges students to renegotiate their views on the role of the teacher in their lives. This examination promotes a pedagogy that develops an understanding of the other. The contact zone approach, as discussed elsewhere in this dissertation, draws on metaphors of conflict. The teacher provides the texts, leads the conversations, and assigns prompts that encourage students to "grapple" with the diversity of the planet. However, in beginning his examination of the Buddha's teachings, Nhat Hanh argues, "When we hear a Dharma talk or study a sutra, our only job is to remain open" (12). Arguably, no teacher utilizing the contact zone approach would argue that students should possess closed minds. However, Nhat Hanh takes it further, "Usually when we hear or read something new, we just compare it to our own ideas. If it is the same, we accept it and say that it is correct. If it is not, we say it is incorrect. In either case, we learn nothing. If we read or listen with an open mind and an open heart, the rain of the Dharma will penetrate the soil of our consciousness" (Ibid.). This approach does not produce an environment based on grappling, clashing, or resisting what Pratt called "highly asymmetrical relations of power" (34). There can be no doubt that through assigning this text the instructor did exert power over the students. However, this text asks students to consider their relationship with their teachers in an empowering way. This text actively shows them that the teacher does not have total power over them, that they, in fact, control their own lives.

Nhat Hanh points out that the teacher cannot give the student truth because, as he would suggest, "The truth is already in you" (12-13). He then explains the different ways 
in which the teachings of the Buddha were transmitted. He discusses the various schools of Buddhism and indicates that when the teachings of the Buddha were finally written down, centuries after he lived, it was in a language (Pali) that the Buddha never spoke. Students find it interesting that the Buddhist scriptures are not to be taken as literal truth. Nhat Hanh tells the story that the Buddha once said "My teaching is like a finger pointing to the moon. Do not mistake the finger for the moon" (17). Thus, "Buddhist teachings are meant to awaken our true self, not merely to add to our storehouse of knowledge" (Ibid.). For Nhat Hanh truth should be transformatory. He argues in Living Buddha, Living Christ that "Dialogue must be practiced on the basis of 'non-self.' We have to allow what is good, beautiful, and meaningful in the other's tradition to transform us" (9). This is perhaps why bell hooks was so moved and influenced by Thich Nhat Hanh's work. In the Forward to The Raft is not the Shore: Conversations Toward a BuddhistChristian Awareness which consists of a dialogue between Nhat Hanh and Daniel Berrigan, hooks indicates that she has spent years contemplating the teachings of Nhat Hanh and finding courage in his words to be a teacher that does not run from truth.

Students are assigned to read Nhat Hanh's chapter from The Heart of the Buddha's Teaching and then respond in an online blackboard post to the following prompt before we discuss the texts in class.

\section{The Prompt}

After reading Thich Nhat Hanh's chapter on "Understanding the Buddha's Teachings" reflect on his comment that "A teacher cannot give you truth. The truth is already in you. You only need to open yourself--body, mind, and heart..." What does 
this remark mean to you? According to Naht Hahn how should we approach learning. Can you give examples?

\section{Analysis}

Thich Nhat Hanh's chapter excerpt on Buddhism presents education in an unfamiliar way for students. They often ask what the correct answer to some historical question is and they quickly look things up on the Internet without much critical thought. They want to know how their grade will be calculated and what happens if they turn something in late. These are very real fears for them. Power relationships guide the American educational system. Reading a chapter that calls for rethinking pedagogical relationships creates difficulties for some students and yet others seem to find it enlightening. One student suggested that she agreed in the importance to read and listen with an open mind and she liked the idea that one does not need a teacher to learn. But, she struggles to accept that "the truth is inside you." This student recognizes the transforming capacity of this approach to education and concluded her essay by suggesting that she felt a positive goal should be "discovering our self." Being open to new ideas is the first step in recognizing the self as the other. This is also illustrated in Lakoff and Johnson's theory that "much of cultural change arises from the introduction of new metaphorical concepts and the loss of old ones" (145). This unit of study introduces students to new metaphorical concepts that then change their perceptions of their identity and their place in the world.

Many students agree with the idea that it is more important to "understand" than to "know" a lot of things. Standardized testing overshadows the lives of students today. 
Some students prefer activities that challenge them to "understand" and think creatively about the world rather than to memorized data. Students commented extensively that education should focus on awareness and self-understanding rather than acquiring a collection of facts that could be tested then forgotten. For example, Lexie suggests that teachers cannot "make you understand something." According to this student, people have to want to understand something in order to "better themselves." Pedagogically, activities that lead students to better the self must include a focus on other awareness in the mind. Upanishadistically speaking, there can be no bettering of the self without understanding and defragmenting the self's relationship with the other. And this cannot be taught by a teacher.

Many students found Nhat Hanh's thesis troubling. Liz writes that she could not agree with Nhat Hanh because to accept that truth was "inside you" meant "you already know everything you need to know which seems almost arrogant." Sasha began her essay stating "I'm not sure what he's saying..." but then she summarizes his statements on the role of the teacher accurately. She endorsed the idea of teachers doing less lecturing then she indicated that listening to others seemed to be key in the development of the self. In listening to teachers, she suggested, we "cannot let them define us as we have to think critically for ourselves and produce our own thoughts." She concludes her essay by warning that people should listen and critically reflect on what they learn. In a rather Krishnamurtian moment she warns us not to have blind faith in what we hear.

Beth suggests that the importance of Naht Hanh's piece was the idea that teachers should teach what they believe to be true. Then the student determines the truth. Notice how this pedagogical approach would impact the relations of power in a classroom. In 
referring to Nhat Hanh's metaphor that Dharma should penetrate our consciousness like seeds, this student interprets this statement as a suggestion that if we let ideas soak in, a person will begin to form their own thoughts about truth. Her suggestion is consistent with Lakoff and Johnson's theory of new metaphor. Specifically that "New metaphors have the power to create a new reality" (Lakoff and Johnson 145). Stan suggests that many people would argue that without a teacher teaching in the classroom, students wouldn't know much. He interprets the text as saying we must, as students, become cautious learners. He argued that personal perspectives often distort what teachers teach. He argues further that Nhat Hanh's theory promotes the idea that a student's selfdevelopment can occur when they feel "encouraged to go out and discover things for yourself and build your own perspective." This particular student's view illustrates the importance of a pedagogy that challenges students to negotiate the multicultural world in which they live. For most of the students in this course there "experiences" consist of existing in an upper-middle class world. Thus, the experiences provided in this course can begin to challenge students to re-theorize their identity in ways that may never again occur for them.

Not every student subscribes to the theory that truth is inside them. Or, that they don't need a teacher. This epistemological construct becomes problematic for themespecially when the educational system focuses so much energy on preparing them for the workplace, not for the life of an ascetic. The following illustration explores this: Once a group of people came to this Non-West History class to observe students. They represented the Mclean County Chamber of Commerce and they toured several local schools that semester. This particular day the class was exploring an excerpt from 
Confucius (The Analects) and specifically his concept of ren (which is usually translated as 'humanness,' $c f$. Armstrong 42). Later the principal indicated that after school this group could not stop talking about how impressed they were with the students in the class. They could not believe that high school students could discuss aspects of ancient Chinese philosophy so intelligently. The thing that amazed them the most was that the instructor didn't "teach" the students anything. We discussed the concept together and the students arrived at their own understandings independent of the instructor telling them what to think. Given these kinds of opportunities, as this example illustrates, students can develop the capacity to think for themselves independently of a teacher in some fields.

Teressa Redd in her chapter “Keepin' it Real: Delivering College Composition at an HBCU" recently made the point that "At its core, Composition 101 is an exercise in conformity" (74). She also suggests that these courses are "unabashedly middle-class" enterprises (81). In the same volume Marvin Diogenes and Andrea Lunsford contend in their chapter "Toward Delivering New Definitions of Writing" that writing in school "has traditionally been strictly regulated" (141). Taking these observations seriously, this unit is an effort to develop an approach to writing assignments that give students freedom. As part of this process, students are encouraged to read Buddhist texts that stress the theory that a teacher is not necessary for a person to understand the world and their place in it. As Kathleen Blake Yancey argues in "Delivering College Composition into the Future" the challenge for teachers of writing is to create a space for students that lead to "learning rather than teaching" (200). This unit on Naht Hanh's interpretation of Buddhist principles creates a good place to start. As multicultural literature is brought in, 
not so students can "grapple" with difference, but to understand the different ways of being. The end outcome becomes a class in which students explore not only the other but also the self from a pedagogical positioning of harmony instead of conflict. Yancey also suggests that teachers should recognize their courses and assignments need to give students a vocabulary that they will "take with them and use during the rest of their lives (206). One can also see that through this unit students did begin to understand (although in a subtle way) the linkages between the educational system which is geared toward high stakes testing and power held by teachers. Through an examination of Thich Nhat Hanh's theory students began to see the school experience as potentially becoming an impediment to their "learning." As Derrick Jensen argues in Walking on Water: Reading, Writing, and Revolution the current educational system (even when multiculturalism is taught) "divorces us from our hearts and bodies and neighbors, from humanity and animality and embeddedness in the world we inhabit, from decency and even the most rudimentary intelligence" (42). Jensen's work encourages student creativity—especially his suggestion that education should be about a person developing the skill to teach themselves "how to think, and how to be in the world" (48; emphasis in the original). Writing and reading provide powerful pedagogical tools in the development of being. Students must understand their ability as a self to be. Thich Nhat Hanh's chapter on the Buddha's teaching complements Krishnamurti and the Upanishads well. Through their written responses students at this point in the course begin to understand the significance of taking this (multicultural) literature seriously, not only as a way of grappling with diversity, but as a way to understand their own being. 


\section{Thomas Merton}

Along with the Thich Nhat Hanh chapter discussed above students are also assigned several excerpts written by Thomas Merton. Many students see other religions (Judaism, Islam, Hinduism, Buddhism, Shamanism) as completely beyond their understanding. Thus, in a Non-West History course that explores the history of the Middle East, South Asia, and indigenous people of the Americas it becomes important to expose students to philosophies from these groups. In Merton, students can see that a Catholic monk looked to Buddhist and Hindu culture and literature as a source of inspiration. Although Merton mentions Krishnamurti only once in his Asian Journals, he respected Hindu sacred texts such as the Bhagavad Gita. In 1966 Thich Nhat Hanh visited Merton at his monastery in Kentucky. Merton later wrote an open letter titled "Nhat Hanh is My Brother" where he stated "I have far more in common with Nhat Hanh than I have with many Americans, and I do not hesitate to say it" (Passion for Peace 261).

bell hooks recommends Merton along with Thich Nhat Hanh in several of her texts. She writes in Teaching to Transgress: Education and the Practice of Freedom that Merton inspires her when it comes to teaching college students. She indicates that she tries to emulate Merton's suggestion that education should be about helping students "define themselves" and live authentically and spontaneous lives in relation "to the world" (199).

The Non-West History students are assigned an excerpt titled "Between East and West" by Thomas Merton, found in the anthology edited by Christine Bochen, Thomas 
Merton: The Essential Writings. This text was prepared from notes he made for a speech given at the Temple of Understanding conference in Calcutta in October of 1968. He begins the essay by suggesting that there exists a "real possibility" of contact on a deep level by all cultures in the East and West (173). He argues that "even where there are irreconcilable differences in doctrine and in formulated belief, there may still be great similarities and analogies..." between cultures and religions (173-174). He understood that on the surface differences are real, yet he went on to claim that "Cultural and doctrinal differences must remain, but they do not invalidate a very real quality of existential likeness..." (174). He believes in the importance of Westerners learning Eastern history and philosophy. He also suggests that Westerners must understand what he called "intertraditional vocabulary" (175). Based on this suggestion, the students in this course study several vocabulary words from Sanskrit so that they can use them appropriately. When they mean to say "action" when talking about the Upanishads, they can use the word "karma" for example. In this essay Merton develops a central point that served as one of the key theories argued in this dissertation's thesis. He calls for "true communication on the deepest level" (Ibid.). This is more than a sharing of ideas, conceptual knowledge, or formulated truth for Merton. This kind of communication must become "communion" (176). A deeper communion, in what he refers to as "a communion in authentic experience" (Ibid.). He states that this kind of communion with the other becomes "the deepest ground of our being cries out for..." (Ibid.). This essay gives students the opportunity to read a Westerner who recognizes that much can be gained by "communing" with the other in a productive way that can lead to the understanding that "this 'I' is really 'not I'" (60). As Merton suggests "This inner 'I' ...is 
always universal: for in this inmost 'I' my own solitude meets the solitude of every other man [sic]..." (81). In this assignment students gain the opportunity to blend several of the texts already experienced in the course. It becomes clear that this promotes a pedagogy nothing like the "contact zone" approach that focuses on conflict (i.e. clashing, grappling; $c f$. Pratt 33-34). Although it should be noted that this dissertation is not arguing here for what Bizzell refers to as the transmitting of a "unitary literature and literacy" model and her theory that "difference is an asset" (166) is part of this dissertation's theoretical positioning. The "asset" of difference grows from the fact of our common humanness. And Merton's approach to humanness requires pedagogy of communion. George Lakoff argues a similar point when he suggests that it is our "connection to the natural world and to each other" (117) that makes us human beings. It is this connection/communion that "demands that we cultivate empathy, responsibility, self-reflection, and a sense of connection, together with a full life based on them" (Ibid.). This new metaphor of communion is the focal point for this prompt.

\section{The Prompt}

Use this online blackboard discussion board post to reflect on the writings of Thomas Merton as they relate to the Upanishads and Buddhism. Why is it so significant that a Catholic monk like Merton would be so influenced by philosophies of the East? How does Merton's view shape your own? Pick one key point that you think Merton makes in this excerpt and expand on it here based on your understanding of the self and the other. 


\section{Analysis}

Brian was the first student to respond to the prompt in the online discussion board and began with the insightful observation that "It is significant that a Christian monk even [paid] attention to Eastern Philosophy." This student summed up how many in the class apparently felt. Many students seem deeply surprised at Merton's text because he treats Eastern thought and religion with such respect that some students struggle believing it. One student indicates in his writing that he could not understand why a Christian monk would read religious texts from another religion. Many of the students this Non-West History course self-identify as being either a spiritual person or openly Christian in the course of the discussions. When these students begin to see that a bigger spiritual world exists in a positive way, they are taking steps toward appreciation and communion with the other. This student elaborated on his comment about how "significant" it is that a Christian would pay attention to Eastern philosophy by stating, “Usually the West doesn't give any respect or attention [to the East] for some reason we don't view it as important or significant. In the West, I think we are so set in our ways which include our foundation on Judeo Christian values and completely brush [off] people like Confucius or the Upanishads of India." This student offers an insight into how this pedagogical approach impacts the possibilities for intercultural communion. It challenges the concept of "American exceptionalism" which now dominates American high school history courses. This student recognizes one of the main goals of this course-specifically the dangers in privileging Western discourse over all others. Yet not every student recognizes this outcome. In future courses when this material is assigned the concept of non-privileging discourse will be approached more carefully to 
challenge students to critically engage the texts in a manner that leads them toward a universalist appreciation for unity through diversity. Many students resist, at a psychological level, the push these texts create toward communion as equals between the self and other. In recognizing this outcome, in the future, this unit will need to be set up slightly differently. Students need to understand the dangers of exceptionalism before they can fully negotiate the fragmented nature of identity construction in much of the West.

David reflects similar ideas and writes "I think it is interesting that a Catholic monk is studying eastern philosophy and it shows that he is willing to recognize 'the other', not only focus on his own perception of the world." This illustrates a recurring theme in many of the texts the students wrote. This student suggests that Merton's work encourages us. He writes that "We must try to understand other people and their philosophy and working together brings the best results. Merton says that we are one and that understanding each other is a key point of enlightened life." This last observation shows insight because Merton never addresses the issue of "enlightenment" in his essay. This illustrates a conceptual leap that the student made that links Nhat Hanh with Merton.

Students read the Merton text later in the semester so it is exciting to see them link his work to texts from other authors we considered earlier in the year. For instance, Kate begins her response by referring to a text by Irshad Manji that is assigned earlier called The Trouble with Islam Today. In the book Manji discusses the difficulties she faces as a Muslim woman who is also a lesbian. She refers to herself as a "refusnik." She refuses to leave her faith; instead she works to transform it from the inside. She has quite a following internationally and students read chapters from her book and watch 
interviews with Irshad Manji which are plentiful on youtube. In the student's response, she writes "Irshad Manji's writings reminds me very much of Mertons work. Manji isn't interested in 'religion,' she is more so interested in 'faith' the dogma related to organized religion is unhealthy for the world. Her response could have given a specific example from Merton or Manji's texts to illustrate her point with evidence. She could also make a reference to Krishnamurti here. Her use of the phrase "hatred is so wrapped up in separateness" fits well within Krishnamurti's view that we think we are separated from the world when in reality the world is us. For Krishnamurti the fragmented lives we lead cause us to not understand the other. This student referred to "inter-religious dialogue" and this appears to be a subconscious linkage between Merton and Krishnamurti. She quotes Merton further, "I cannot make the universe obey me. I cannot make other people conform to my own whims and fancies. I cannot make even my own body obey me." She then analyzes this excerpt by arguing that "Merton stated this with an open mind and heart. This quote directly correlates to how one can truly grow." This student's response provides an example of how insight can be gained through blending previous concepts with current readings. She confirmed that communion can result from a detailed study of multicultural texts in an open classroom environment. Linda Flower observed in "Talking across Difference: Intercultural Rhetoric and the Search for Situated Knowledge" that intercultural rhetoric "welcomes differences...in order to empower underrepresented, less authoritative, and traditionally marginalized ways of speaking" (44). This particular student seems to recognize the importance of what Flower called "talking across difference" (42). This student took the prompt seriously and she refers to other texts that she read previously in the semester. She develops the important skill of recognizing that 
texts and units covered in school are actually applicable in her life. As Gerald Graff argues, students "need to experience an intellectual conversation in order to join it...the curriculum needs to represent that conversation in a more connected way" (80). This student recognizes that everything she read and thought up to this point became part of her cognitive repertoire in answering a prompt. She practices "joining the conversation" with positive results.

The overarching thesis of this dissertation demonstrates the possibility of approaching multicultural education not from the Contact Zone but from an approach that recognizes the Upanishad concept of "you are that." Biff, a particularly insightful student, seems to recognize this in his response to the prompt, although subtly. He begins (as many students did) in reflecting on how Merton's respect for Eastern philosophy was "huge." He writes that "Merton accepts and places value in many [Eastern philosophies] meaning that a common link can be found between them and Catholic religion. People so easily point out the differences between themselves and the people that they consider to be 'the other' but we seldom take time to look at how we are the same. This is a really important work." He cites Merton's lamentation that "It is not only our hatred of others that is dangerous but also and above all our hatred of ourselves: Particularly that hatred of ourselves which is too deep and too powerful to be consciously faced. For it is this which makes us see our own evil in others and unable to see it in ourselves." This student recognizes a key point Merton made about the impact of hatred. He uses this reference to back up his claim that we seldom look at our common humanity. The student does not refer to Merton's call for "communion" with the other (which can lead 
to a better understanding of the self) but he expressed a clear view that Merton offered him a different (i.e. better?) way of thinking about the 'other.'

Many students wrote about Merton's “acceptance.” Where Krishamurti writes "The world is you," Merton writes "We are the world." And the Upanishads posit "You are that." Bart interpreted Merton's point that "We are the world" to mean that "we are merely little parts in a larger metaphysical being...[Merton] says that everything around us impacts who we are but that everything we do impacts the other. This definitely reflects the idea of the self and the other and reiterates my belief that we all serve as a whole made up of many individuals." This really is a profound statement for a high school student. Granted, he might have discussed what those "beliefs" were in which he refers to support his view but the fact remains that this student seemed to share a very Upanishadic vision of humanity that derives from an ontology of "you are that." Another student went so far as to recognize that "Merton's philosophies are very similar to the Upanishads philosophy and the traditional Buddhism views." This student attempts to link three conceptual frameworks. Unfortunately, when this student writes "I agree with most of Merton's views, so my views haven't really changed after reading his work" he does not give any indication of which of Merton's views he agrees with, or which views he does not agree with. He does however conclude his response by writing "I also feel that the self and the other are one." This student needed to provide more analysis to illustrate how he came to this conclusion, but his response illustrates that a high school student can subscribe openly to the Upanishadic concept of "you are that."

Many students write about Merton's “open-mindedness" as a very positive aspect of his theory of communion. For example, Sue begins her response in a rather classic 
rhetorical approach where she cautiously stated "I understood Thomas Merton to say that people are meant to respond to the calls of God through contemplation." Notice how she set up her response. She did not jump right in and say something like "here is what Merton says......and I agree...." She quoted him in his observation that the "deep transcendent self" can awaken "only in contemplation." She then links this statement to the Upanishads and writes "An important element to the Upanishads is the idea of the self and that there is a self that [has] to be built up through a higher knowledge that can only be reached in a specific way. Merton argues that this specific way is contemplation, and I believe that this deep thought (contemplation) is used to read the higher knowledge which I think is similar to what is expressed in the Upanishads." This student provides an interesting example. When her group did their presentation earlier in the semester on a specific Upanishad she did not use a power point or utilize any other kind of electronic medium. Instead she painted a portrait that illustrated the levels of consciousness the self must transcend. She approached the instructor one day and asked if it was acceptable for her to paint a picture and then describe it to the class and not use any technology. Her painting hangs in the Social Studies office today. Merton never mentions the Upanishads in the text students read for this course, yet she made the connection.

Maxine Hairston once wrote in her controversial essay "Diversity, Ideology, and Teaching Writing" that for the most part writing teachers "look for ways to promote genuine diversity in our classes..." (186). She argues that the main goals of writing teachers must focus on helping students "learn to write in order to learn, to explore, to communicate, to gain control over their lives" (Ibid.). Many of the responses student produced illustrate that they made connections in a way that illustrates their thinking 
about assigned texts in bigger ways than just classroom writing assignments. They drew connections between multiple texts from various units and wrote about them in ways that showed they took them to heart. In 1995 the CCCC Committee on Assessment published a paper called "Writing Assessment: A Position Statement." One of the positions is that "writing assessment is useful primarily as a means of improving learning" (432). The committee argued that "essay tests that ask students to form and articulate opinions about some important issue... without time to reflect, to talk to others, to read on the subject, to revise and so forth...encourage distorted notions of what writing is..." (433). With these writing prompts, students have the time to read, to talk, to think, and to write in ways that encourage them to creatively think about the texts an enhance their experience of the self and the other. 


\section{CHAPTER VII}

\section{“WAS JESUS A BUDDHIST?” A UNIT IN SECONDARY SOURCE ANALYSIS}

This chapter provides an analysis of student writing in response to their reading an academic article from the social sciences. This assignment differs from previous assignments that this dissertation examines. Earlier chapters analyze student writings in which students engage with primary sources and negotiate outcomes that derive from specific philosophic constructs (for the Upanishads students applied tat tvam asi; for Krishnamurti they analyze fragmentation and conditioning; for Nhat Hanh students examine Buddhist pedagogy; and for Merton students deconstruct the concept of communion). With this assignment, students learn to navigate an academic piece of writing on a controversial historical topic. This exercise gives them an opportunity to respond to a prompt that fostered creative thinking and challenged them to develop new insights. An important text in the development of this chapter was Because Writing Matters: Improving Student Writing in Our Schools by the National Writing Project. In this text (which was co-authored with Carl Nagin) The National Writing Project calls for teachers to give writing assignments that help students develop "higher-order thinking skills: analyzing, synthesizing, evaluating, and interpreting" (22). They argue that the virtue of writing is that it "requires that students move beyond rote learning and simply reproducing information, facts, dates, and formulae. Students must learn how to question their own assumptions and reflect critically on an alternative or opposing viewpoint" (2223). This chapter outlines an application of this strategy. 
In an earlier chapter this dissertation explores James Loewen's text Teaching What Really Happened - specifically on his call for teachers to engage students with readings and activities that produce "empathetic understanding" (87). Lowen laments (much like Graff) that high school students often times have never been given experience engaging academic research. He speaks of the dangers of basing a course around rote memorization and instead he suggests (much like the National Writing Project) that "Teachers can create 'aha moments"” (93) by asking students how they would relate material from previous units to a current unit—-this will lead to what he terms "deep thinking." This unit challenges students to think creatively about an academic article on Jesus and his relationship with Buddhism. The prompt for this unit creates a writing experience that enables students to read scholarly work then craft a response that shows an open mindedness promoted in previous units. This assignment challenges students to develop new insights based on previous understandings. The pedagogical approach for this unit derived from Kiuhara et al. as well. They show in their article "Teaching Writing to High School Students: A National Survey" that students feel they "mostly write to convey information or demonstrate knowledge, seldom using writing to develop new insights" (150). One final pedagogical aspect of this activity derives from Bob Broad's suggestion in What We Really Value: Beyond Rubrics in Teaching and Assessing Writing that teachers almost never include interesting, lively, or creative on their assessment rubrics (he draws heavily on Grant Wiggins here). The pedagogical approach utilized in this assignment draws on the theory that after exploring texts that promote renegotiating ideological constructs of the self and other, students will be more open to a controversial academic view of Jesus. Thus, their responses will demonstrate 
some of the themes and topics that previous units introduce through-out the semestersuch as de-fragmentation, tat tvam asi, or the recognition that communion can bring about creative insights into the historical record.

\section{Was Jesus a Buddhist?}

There is a growing collection of literature dealing with the topic of Buddhism and its relationship with Christianity. New Testament scholar Marcus Borg is perhaps the best example from the West. His text Jesus and Buddha: The Parallel Sayings catalogues a collection of sayings attributed to Jesus and the Buddha and Borg pairs them in a way that makes for easy understanding (for example, the first parallel saying he cites is Luke 6.31 "do to others as you would have them do to you." In parallel he lists Dhammapada 10.1 “consider others as yourself”). In Without Buddha I Could Not Be a Christian theologian Paul Knitter offers another example, although much more philosophical and academic. The idea that there exists a linkage between Jesus and the Buddha has grown in popularity from the Eastern perspective as well. Thich Nhat Hanh's Living Buddha, Living Christ and His Holiness The Dalai Lama's The Good Heart: A Buddhist Perspective on the Teachings of Jesus provide clear examples. The above mentioned texts tend to explore the sayings of the Buddha in relation to Jesus (the Buddha lived 500 years before Jesus). This line of inquiry influences James Hanson to pose the question "Was Jesus a Buddhist?" which became the title of a paper he published in the Journal of Buddhist-Christian Studies in 2005. He answers his own question in the last few lines of the paper by stating "When nineteenth-century missionaries translated and read ancient Sanskrit and Pali documents in India, they began to call Buddhism the Christianity of the East. But Buddhism came first, 500 years before 
Christ. The more accurate dubbing is to call Christianity the Buddhism of the West" (87). Many of the students enrolled in this Non-West History course self-identify as Christian during class discussions and this article gets them reading outside their comfort zone. Further, it provides them a chance to explore the historical record in a more objective way.

Hanson begins his article by suggesting right away that "there is convincing evidence that he [Jesus] was also a Buddhist" (75). He indicates that historical and textual evidence support this claim. In fact Hanson further suggests that "The real historical question is not if he [Jesus] studied Buddhism, but where and how much he studied Buddhism, especially during his 'lost years'” (Ibid.). Hanson then breaks down the compelling historical evidence yet not well known to non-specialists. He describes how 360 years before Jesus was born Alexander the Great had extended his empire through Palestine all the way to India. He then documents the extent of trade between China, India, and the Hellenistic Greco-Roman world via the Silk Road which ran through Jerusalem. Hanson concluded that the people of Palestine, during the height of the Roman Empire, were familiar with Asian religions such as Zoroastrianism and Buddhism because people practicing these faiths actually lived in the region. Biblical texts even have Zoroastrian priests attending the birth of Jesus (the Magi). Philo of Alexandria, a contemporary of Jesus and writing in Egypt, included a detailed description in his text On the Contemplative Life of a group of people living near Alexandria that he refers to as "the therapeutae." Most scholars today recognize that the therapeutae were probably a community of Buddhists living in Egypt in the time of Jesus. The Indian Buddhist king Ashoka (who was crowned king in 273 BCE) sent Buddhist missionaries 
throughout India and even to Syria, Egypt and Greece. Will Durrant suggests in his seminal work Our Oriental Heritage (published in 1935) that these missionaries "helped to prepare for the ethics of Christ..." (449). Philo offered a remarkable description of the therapeutae. They lived lives unlike the indigenous Semitic peoples or the Roman authorities. He indicates that for large parts of their day they were "devoted wholly to meditation on virtue" (3.28). He describes them as vegetarians, an unusual practice in the Hellenistic world. He also states, "In short they practice entire simplicity, looking upon falsehood as the foundation of pride, but the truth as the origin of simplicity..." (4:39). Philo makes clear that the therapeutae don't drink wine. Only the purest water. This is such an outlandish practice that he prefaces his remarks by stating "I know well that some persons will laugh when they hear this..." (9.73). He then indicates that that they did not drink wine. Even the older contemporary of Jesus, the Greek geographer Strabo, wrote a detailed geography (Book 15) of India based on information he gained by talking to people he found who had been to that region. Strabo also read written accounts from soldiers in Alexander's army. Hanson cites an impressive collection of textual evidence to support his theory that Jesus had contact with Buddhists.

After reviewing the literature that demonstrated Buddhists lived in the vicinity of Palestine at the same time as Jesus, Hanson then provides a discussion on what historians refer to as the "lost years" of Jesus. The book of Luke (Ch. 2) describes a scene where a young Jesus lectures the rabbis in the temple on the law and they are amazed at his knowledge. Jesus then disappears from scripture and does not re-emerge until he is roughly 29. Scholars call the 17 missing years the "lost years." Hanson then reviews the historic evidence which suggests that Jesus might not have been in Palestine during that 
time. One theory suggests that Jesus could possibly have been in India studying Buddhism. In this section of the article he discusses the Arabic and Hindu literature that talk of Jesus being in India. He concludes that the argument that Jesus traveled to India is much more "new age" than academic. Hanson suggests, from a scholarly standpoint, that most of this literature is fraudulent.

Hanson then compares the mythological elements that link Jesus with the Buddha. He includes a lengthy list of similarities such as both are born from a virgin mother. Both are tempted by the devil. Both fast in the wilderness for forty days. Both advocate peace and teach using parables Hanson then examines the parallel sayings between the Buddha and Jesus. Here he draws heavily from Marcus Borg. One example is found in Jesus's statement: "A foolish man, which built his house on sand," and the Buddha's statement: "Perishable is a city built on sand." Hanson cites an extensive list of comparisons. He then dismisses a universalist interpretation of the nature of the parallel sayings that states that it should be expected that sages would teach similar things because they are universal truths. Unlike Borg, Hanson argues that this cannot be due to coincidence. Hanson further argues that "ethics and laws vary widely among cultures, at different times within given cultures, and by different spokespersons or subcultures within given cultures" (85). He concludes the article with the argument that "The parallelisms between the teachings of Jesus and Buddha are unique, not universalist. There are no such parallelisms between what Jesus taught and what was taught by Zoroaster, Tao, Confucius, or Plato and the ancient Greek Philosophers" (86). Thus, to answer his original question "Was Jesus a Buddhist?" he states that "the answer is not yes or no, but rather to what extent Jesus was or was not a Buddhist" (Ibid.). It is telling that in 1979 eminent New Testament scholar 
Elaine Pagels postulates in her book The Gnostic Gospels that "What we call Eastern and Western religions, and tend to regard as separate streams, were not clearly differentiated 2,000 years ago. Research on the Nag Hammadi texts is only beginning: we look forward to the work of scholars who can study these traditions comparatively to discover whether they can, in fact, be traced to Indian sources" (xxi).

Students read Hanson's article toward the end of the semester. In their writing they have the opportunity to apply some of the concepts they studied earlier in the course-such as being open to ideas that require them to renegotiate their understandings of those concepts in relation to their own lives. As Lakoff and Johnson argue, "changes in our conceptual system do change what is real for us and affect how we perceive the world and act upon those perceptions" (145-146). This unit required them to look at a controversial historical topic and to read and process an academic paper and develop the skill of creative insight. Their struggles are clear in their response to the prompt. Yet, for many students, this unit leads them into a deeper appreciation for the complexities of academic discourse. The writing prompt assigned is given below, followed by a critical analysis of their writing.

\section{The Prompt}

James Hanson suggests that there is convincing evidence that Jesus was a Buddhist. This is a fascinating paper, is it not? What historical evidence does he cite to back up his thesis? What textual evidence (both Christian and Buddhist) does he cite to suggest Jesus was familiar with Buddhism? Explain his conclusions? Finally, analyze his argument. Based on the evidence he cites does he make his case? What do you think 
of this paper? Let's get a conversation going here in this discussion board. After you comment come back to this page and read over your classmates comments before we have our in class conversation.

\section{Analysis}

This unit of study exposes students to academic discourse and also engages them to think and write creatively about an academic article as it relates to their own life. Most students follow the prompt closely and write rather generalized summaries of Hanson's argument. They cite the evidence (both textual and historical) that Hanson uses and they summarize his argument that Jesus could very well have been influenced by the Buddhists he knew. Many students seem to neglect the historical evidence though when they indicated whether or not they accepted his argument. For example, Brad writes "Hanson states that Jesus may very well have been a Buddhist. I believe that he may very well have run into Buddhism and adapted some of its beliefs as his own but I don't agree that he was a Buddhist." This student picks up on the fact that Hanson stated that Jesus would have known Buddhists but he never indicates that Jesus was a Buddhist so in the last sentence when the student writes "I don't agree that he [Jesus] was a Buddhist" complexities emerge that seem to indicate that the student did not fully engage Hanson's argument. Many students compose similar kinds of statements.

The remaining pages of this analysis focus on examples from student writing samples that show where they offered insightful or creative comments. Katelyn, after summarizing Hanson's argument and evidence indicates that she could not accept his case. Her comments show a willingness to engage an academic article in a way that 
illustrates comfort and a willingness to challenge an argument. She writes, "I disagree with Hanson because the claim that Jesus and Buddha have similar teachings isn't a strong argument because they both revolve around compassion so naturally their teachings are similar. Also, Hanson only focuses on the lost years of Jesus, rather than his entire life which must be taken into account when comparing him to Buddhism. I think Hanson makes a good argument but his jumps to conclusions are sometimes too big for me to believe." She offers a response that illustrates her main problem with Hanson's theory which derives from his limited use of the historical evidence. According to her, because he only focuses on certain aspects of Jesus's life, this leads to an inaccurate interpretation and the jumping to conclusions.

Fran tries to rationalize through the article by writing that the similarities between the teachings of the Buddha and Jesus could actually be "God's hand." She argues that this "would explain why some things, such as the Golden Rule, can be found all over the world in all different religions, and why Christ would have taught similar things as any Buddhist monk might say." Hanson actually addresses this "universalist" approach and refutes it because there are too many coincidentals. This student is actually more in line with Marcus Borg's argument (although Borg's texts are never assigned in this course). This rationalization seems to miss an entire section of Hanson's article, it shows that this student struggled to make the conceptual leap required to write this prompt without falling back on her preconceived notions of Jesus. During the in class discussion of this article many students made this point. This creates an opportunity to discuss with them how to read and analyze academic writing in a critical way based on objective standards. This particular student ignores a section of text that countered her position and then she 
offers an interpretation based on her own personal religious view. This student's response helps in rethinking the pedagogical approach utilized in the class discussion. In teaching this unit a conversation on the difference between analyzing a primary source and a secondary document written by a historian needs to be included.

One of the important aspects of an online discussion board post format is that students who tend to be quiet and reserved in the class have the opportunity to state their views in the discussion board more comfortably. After a brief summarization of the article Jake submits that he thought Hanson is "on to something." He states "And I know some people would get upset if I said this to them, but one has to remember that there is a difference between belief and knowledge. One may believe that Jesus was not a Buddhist, but, the fact is, tat e may have been. I tend to take more of an agnostic look at things related to religion, however, so my opinion is probably shunned by many people. But, from where I sit, you cannot absolutely prove that Jesus was a Buddhist or that he wasn't. And even if you could, not many people would accept it; It would shake the foundations of Christianity."

This student stretches out his thoughts and shows a willingness to think creatively. He seems to relish the idea that people would not like what he had to say and that gave him a deeper sense of strength and freedom. It is interesting how the last sentence of his post includes the phrase "shake the foundations." This echoes the seminal text in systematic theology by Paul Tillich The Shaking of the Foundations (published in 1948). In one of Tillich's last essays (published in 1966, one year after his death) he concluded by arguing that we must be open to other religions and ways of being. He states, "Above all, it lies in the openness to spiritual freedom both from one's own 
foundation and for one's own foundation" (Theologian of the Boundaries 323). This student feels free to write a text that other students would find uncomfortable. He engages this material and provides an analysis that is meaningful to him. It is doubtful that he could have expressed these thoughts in an in class discussion. The online component of this writing assignment allows him to provide a deeper analysis that showed how serious he took the assignment.

Not all students felt Hanson's article made the case that Jesus could have studied Buddhism. For example, Sam writes "James Hanson did not persuade me to think Jesus was a Buddhist. Hanson tried to make a case with a lot of, 'what if's' during Jesus's lost years. It is possible Jesus and Buddhism occurred during the same time and place. During this time it is possible that Jesus was influenced by Buddhism, but it is all assumption. Hanson's theory is plausible, but I believe God already knows everything." He reiterates that Hanson's argument is all "assumption," thus he cannot accept that Jesus had been influenced by Buddhism. He then states that Jesus didn't need to go to India during his so called "lost years" or talk to Buddhists in Palestine while he was growing up because Jesus was God and knew everything about Buddhism already. So, he concludes that Jesus did not study Buddhism, because he already knew everything about it. This might not stand up to secular humanistic historical analysis, but this student makes an emotional argument. He takes the prompt seriously and makes an effort to write a passionate response.

Anne writes “This article is very dependent on 'what if's' and 'consider this's.' However he makes a good argument for the possibilities and opens religious minds to a new idea." This particular student's response lacked a detailed explanation of what he 
meant by the term "possibilities." This student offers a less hostile response to the article but still doesn't like the concept of "what if" in a historical paper. To many students the study of history revolves around getting a fact right or knowing an answer, not speculating creatively about the past. Charlene takes it a step further and claims that "To say that Jesus was a Buddhist would mean he subscribed to their spiritual beliefs of the afterlife and things of the like. I think it's definitely safe to say that Jesus was aware of Buddhist teachings (whether he knew them already being God or studied them on his own), but I think the article does not fully support the idea that Jesus was an actual Buddhist." Here we see a student suggesting that Jesus would know everything about Buddhism because he is God after all. She wrote that Hanson's article "does not fully support the idea that Jesus was an actual Buddhist." Most of the students who are uncomfortable with the idea of Jesus being a Buddhist seem to also find Hanson's article generally problematic. In future sections of this course there needs to be more of a focus on the importance of reading academic articles in a more critically objective manner. Many students miss key aspects of the argument because they could not process the material because their emotional responses overcame their thinking. When teaching this text again, more time will be spent in class examining how a student of history can read articles and dissect the evidence and arguments as laid out by the author. Students need to understand that they should feel free to disagree with an argument but that they must first give it their full attention. Emotional responses based purely on feeling devoid of historical understanding are not appropriate responses in the social sciences.

In the same line of rationalizing through Hanson's paper Scott wrote "Though James M. Hanson gives certain persuasive ideas about Jesus being a Buddhist such as 
Jesus' 'lost years,' I don't think that it's actually true. They might have similar morals and teachings, but it's likely due to the fact that both Buddha and Jesus were unique and remarkable individuals. Same ideas can appear almost at the same time, in the different parts of the planet and not be connected." Again, this analysis fits well with what Marcus Borg suggests (that it is largely coincidental). This student offers a good explanation though. For example, he states that Hanson gives many "persuasive ideas" about Jesus being a Buddhist but he never cites a specific example from the text. There are many persuasive (and historically and textually accurate) examples cited by Hanson. So, when the student writes "I don't think that it's actually true" and then provides no examples or explanations as to why he doesn't think it is true, his argument appears shallow. Many students who did not like this article made rather brief explanations as to why, like the student mentioned above.

Some students seem to completely miss the historical evidence component of this article while others picked it up perfectly. Ted writes "Jesus may have been a Buddhist due to his similar teachings and values. Both he [Jesus] and the Buddha said similar things about how to love and how to be a good person. While Jesus may (and probably wasn't) an actual Buddhist he seems to and was most likely in contact with Buddhists." This student caught on to Hanson's argument and evidence. He went on to write "Buddhists were in the Middle East at the time and so he probably talked and learned from some of them. Jesus was probably not a Buddhist but many of his teachings are very similar to Buddhism so he was probably influenced by Buddhism." This student uses the word "probably" on several occasions in his writing - a common phrase in historical speculative writing like Hanson's piece. Jane took issue with this concept of 
"possibility" in the historical record. She seems to want a clear answer and appears frustrated at Hanson's rhetoric. She writes "no one really knows because as good as his idea about Jesus is, he can't actually prove it with real textual evidence that says he learned Buddhism, he can only look at what happened and infer from there." This student offers a good summary of how historians work (especially with the distant past). She wants proof and historians can only offer interpretations based on inferences deriving from the textual record (and possibly archaeology and other social science data). Ironically, students don't tend to read a chapter in a textbook (specifically those 1000 page survey textbooks that get used in high school history classes) and then shout out, "I want proof for what these textbook authors are writing about." Yet because this is so close to home and controversial, she demands proof which does not existence, of course, in the historical record. Yet these students are in the minority. Many students indicate in the class discussion that they appreciate this article because they find that it engages them in a controversial topic that they find interesting and relatable to their own lives.

As stated earlier in this chapter, this unit gives students the opportunity to engage the practice of academic conversation (as Gerald Graff would suggest). It is important to keep in mind that as a history teacher's job is to prepare students to write in college history courses. James Loewen points out that college professors “don’t respect or reward students who recall 6,000 textbook twigs from high school" (31). He argues that getting students into the academic world of reading and writing — as was done in this unit—will "stand students in better stead in college history courses. Indeed, students who can read critically, write coherently, create tables and so on, will do well in most college courses, not just history" (Ibid.). With this article students fall back on previous texts 
they studied and approach a scholarly work in history through the lens of concepts studied previously. While not every student liked the article many show a willingness to think about it in creative ways.

This unit allows students to begin critically reflecting on how academic writing differs from primary sources. The pedagogical sequence of the course led to this point. Students study the Upanishads and the ontological construct tat tvam asi (you are that). This text challenges them to examine how identity construction might change the way the self-interacts with the other. They then study Krishnamurti's theory that our lives are dominated by our inability to see past the fragmentation that divides the self and the other. Following this, students study Thomas Merton's argument that communion with the other could lead to empathic understanding that the self and the other are undeniably linked. These units of study engage students with texts and concepts that challenge them to re-negotiate their own concepts of being. In teaching this final unit on Jesus and Buddhism the pedagogical goals derive from the above mentioned foundations. Many students saw their own beliefs blending with beliefs with the other in an academic piece of historical writing. In constructing the sequence of texts in this way an attempt is made to create an activity that gives students an experience that built to this culminating unit. At first glance the results seem disappointing. Many students became hostile to the article and argue, rather emotionally against it. However, upon closer examination it seems clear that while many students did not agree with Hanson, they at least were open to the possibility of his thesis. Further, it also seems clear that previous units create openness in many students that might not have existed if they did not study the above mentioned texts. Negotiating identity is a complex activity. These units give students 
practice creatively thinking about complex ontological constructs-in line with the National Writing Project's call for writing teachers to give assignments that require “analyzing, synthesizing, evaluating, and interpreting" texts (22). And while not everyone is open to the overall goal of fostering empathic understanding, many students see that through interpreting texts they might derive different understandings of the other. 


\section{CHAPTER VIII}

\section{CONCLUSION}

The research questions this dissertation investigates began to take shape years ago while working on a Post Baccalaureate Certificate in the Teaching of Writing at Illinois State University. While seriously thinking about how to utilize writing better in history courses Kathleen Blake Yancey's call for teachers to use composition to help create the citizen writers of the world became the focus. A philosophical and pedagogical model was found in the Upanishads and the work of J. Krishnamurti. Putting together these history courses, and theorizing about assessment strategies, Further Wiggins and Broad's argument that teachers should consider including insightful, creative, and risky to be assets in student writing an important component of how an approach to writing might work. Creating an environment based on freedom - the kind recommended by Rollo May and Carl Rogers-where students could stretch out their minds and think creatively through writing became the goal. This led to questions problematizing several aspects of multicultural education as it is often taught through the lens of Pratt's "contact zone" methodology. The approach this study utilizes in the teaching of writing needed to be different. And while the impact of Pratt's approach on multicultural pedagogical practices is extensive this study offers a different pedagogical construct. Using a framework based not on grappling with diversity, but showing the possibilities through guiding students through texts in a way that would help them develop (through writing) empathic awareness and de-fragmentation through communion with the other became the 
goal. Thinkers like Thomas Merton, Thich Nhat Hanh, the Dalai Lama, J. Krishnamurti, and Jeremy Rifkin, and Arthur Schopenhauer all promote an ontology that the Upanishads call tat tvam asi "you are that." Brain research now provides valuable evidence supporting what the above mentioned theorists have argued (specifically through the findings related to mirror neurons). All of this is influential in the development of this study's composition pedagogical methodology. This dissertation provides several chapters detailing examples of writing assignments students undertook. The data illustrates the impact of this approach to using composition differently in a social science high school course. Any teacher looking to rethink the Contact Zone approach to composition pedagogy can find new and meaningful insights in these chapters.

\section{Recommendations}

In an earlier chapter this dissertation reviews the text The Function of Theory in Composition Studies by Raúl Sánchez. The most promising aspect of Sánchez's conclusions is his struggle to theorize the "something else" that "lurks behind the veil of

writing to record and secure. In such a system, language — and writing — can only ever be a secondary consideration..." (32). Through-out his book Sánchez reviews the shortcomings of various approaches to theorizing in composition studies. He takes serious issue with hermeneutics and laments that "in the place of writing, concepts such as knowledge, ideology, and culture have claimed composition theory's attention as scholars have tried to explain how they appear to work through discourse" (4-5). He urges a "new approach to theory" throughout his text as he surveys the vast literature in composition studies. In the final chapter of his text he states "As composition theorists, if 
we work in the realm of agents, subjects, or consciousness, then our descriptions of writing will only ever present it as an instrument, as a means by which something else is arrived at (94). He further argues, "But if we give up the deep-seated and ultimately unfounded assumption that writing is a function and product of individuals interacting with the world, with culture, with tradition, or even with themselves, then we might begin to address the many implications of the proposition that writing is a phenomenon of constant (re)circulation, one that promises the representation of something else but never actually delivers" (94-95). For all of this text's insights, a shortcoming is that he never seems able to define the "something else" that writing is about. He concludes his book by stating that he is not trying to offer a theory of writing in the first place. His book is about the "grammar of writing" (100). He acknowledges that he has broken down some of composition theory's "cherished concepts" and produced a text that is paradoxical because while he has burdened composition theory with his "grammar of writing" approach, he has not actually theorized about writing (Ibid.). This leads him to conclude: "At any rate, we know that perspectives have limitations - that, as Burke notes, '[a] way of seeing is also a way of not seeing" (Burke quoted in Sánchez Ibid.). Sánchez and this dissertation are theorizing about writing from two very different epistemological stances. Instead, the conclusions of this study suggest that as compositionists like Sánchez theorize about the grammar of writing and the search for something else, they might benefit from also studying the epistemological constructs advocated by Krishnamurti and the Upanishads.

In his text Sánchez reviews an impressive amount of literature on composition, and while he discusses concepts like consciousness, self, other, knowledge, culture, and 
ideology he is limited in his analysis because he draws almost exclusively from Western theorists (with the notable exception of Spivak and Bhabha—both trained in the West though—Spivak at Cornell and Bhabha at Oxford). This dissertation suggests that theorists might benefit from Non-Western concepts that are outlined in this dissertation. As Sri Chinmoy suggests of the epistemology of the Upanishads, "We have to know that this 'nothing' is actually something beyond the conception of the mind...It transcends our limited consciousness" (58). Perhaps there is room in Sánchez's ontology for a recognition that the something else is beyond categorical theorization. This dissertation also illustrates the potential that Krishnamurti's philosophy has for the teaching of writing. Sánchez struggles with conditioning—as most of us do. His concern with writing as it relates to knowledge, ideology, and culture show the power of a fragmented conditioning. As Krishnamurti writes "As long as we are concerned with principles, ideals and methods, we are not helping the individual to be free from his own selfcentered activity with all its fears and conflicts" (Education and the Significance of Life 21). He further states that "The highest function of education is to bring about an integrated individual who is capable of dealing with life as a whole" (Ibid. 24). Thus, writing assignments given in thus study are not about knowledge, ideology, or culturethe focus of Sánchez. Even when students write about an academic article there was an ontology of something else occurring. Empathic awareness, insight, de-fragmentation, wisdom, a recognition of self and other, all of these things were happening. Sánchez is correct that all perspectives do have limitations; this is due to the conditioning nature of knowledge, ideology, and culture. For Krishnamurti the first question is "Are you aware that you are conditioned? (Freedom from the Known 25; this became a first question for 
the students also). This could be a first step in overcoming the fragmentation that limits our ability to theorize writing differently, to get at the something else. This study provides evidence that demonstrates that through writing assignments focused on the promotion of the Upanishadic concept of tat tvam asi students can in fact gain an empathic awareness of the self and the self's relationship with the other.

History teachers as well as English teachers reading this dissertation no doubt recognize that the pedagogies we employ in multicultural education are important. This study outlines an alternative pedagogy to the Contact Zone methodology of multicultural education, which focuses too much attention on conflict. The conclusions offered here suggest that when the focus is communion with the other then the ontological understanding becomes "you are that." This creates the possibility to re-negotiate multiculturalism as a way to promote empathic awareness and unity through diversity.

In the course of doing the research for this dissertation moving away from Continental philosophers (like Foucault, Marx, or Derrida for example) and American thinkers (such as Rorty, Fish, or Dewey) made space for the equally important thinkers from outside the epistemology and ontology of modern Western thinkers whose work tends to dominate philosophical and pedagogical treatise. Many teachers might benefit from exploring the immensely important texts that are commonly understood in the East but virtually ignored in the West. There is an impressive array of Eastern philosophical literature that can help teachers re-shape their views on multiculturalism. 


\section{Restating the Research Questions}

In the course of this study students read a diversity of texts that encouraged an empathic awareness based on Upanishadic logic. As outlined in the introduction of this dissertation an overarching question this study investigated asked what the impact of the Upanishads might be on student understanding of the self. A second research question investigated how Eastern texts that promote empathic awareness might impact students as they attempt to create creative insights. The final research question of this study asks how students respond to the Upanishads overall and why did they respond the way that they did. The previous data chapters analyze student writing in relation to these questions and concluded that an Upanishadic approach to multicultural literature can lead students to embrace empathic awareness through a focus on tat tvam asi (you are that). This approach leads to a different outcome than that of the Contact Zone which derives its foundational principles on encouraging students to grapple with diversity in a rather confrontational manner. At the end of the semester students write self-reflective essays that provide insights into these research questions. As is clear in the following section of this chapter, many students were open to re-negotiating their identity construction through the lens of Upanishadic philosophy which should be expected based on Lakoff and Johnson's theories involving the creation of new metaphors when people are exposed to cultural diversity. Yet, several students resisted. They could not accept that the self is the other and that individualism needed to be re-conceptualized. In future sections of this course more time and discussion on the complexities surrounding the topic of individualism as it relates to unity in diversity will be employed. 


\section{Students Reflect on Their Understandings}

Student responses varied but two themes did emerge in their overall reflections. The first emergent theme was change. For example, Stan writes that he had recently switched churches and was "really striving to change who I am." He feels that the texts he read during this class helped him recognize that "we are all connected and it makes the world feel like a lot smaller place now...we need [to] help the world change, but before we can help other people change we need to change ourselves." In his quest to renegotiate his self-identity this student found that connections with the other can be a good starting point. Interestingly, Brian argues that the course "didn't change me on who I am but it certainly makes me look at things differently." Even though he argues that he didn't change who he felt he was as a person, he does indicate that he looks at the world differently. He does not specify how, but it seems that he is implying that he is more open to understanding the other. Many students expressed similar views that the course had in fact altered the way they now think of the self in relationship to the other.

A second, and more strongly represented, theme was connection. Steve argues that he felt that "individualism is over-rated in a sense, because it isolates us from the rest of the world. The barriers put up (even subconsciously) don't allow us to be empathetic towards those that may be different from us...It's that human desire to feel wanted that makes us human beings. It's critical that we begin to recognize the other as our self." This insight derives from this students understanding of the Upanishadic concept of tat tvam asi and suggests that this student has developed a deeper empathic awareness through an examination of the texts read during this course. Kate suggests that she "really became aware of how much we really are connected and how we should really 
think about that when we act." She further writes that the course "made me see that we are all one community and one world race and even kind of a family and that we should be out to help each other and not just ourselves." Her response encapsulated the core teaching of the Upanishads and the other texts read during the class. For her the world is more than the individual self, it is a symbiotic community.

Continuing with the Upanishadic theme of connectivity one student suggested that the course "changes the way we think and treat other human beings and things. If we are all connected in some way, the other can become the self." A further observation suggested by Charlene showed a similar mindset. She asks, "If we all thought of other people as ourselves and thought of what it would be like to be in their position, the world would be a lot more nice and peaceful place." She identifies in her response the complexities of re-thinking the self and the other. Yet she further suggests that "the topic can be made complicated with the Upanishads [and] mirror neurons...But when it comes down to it why can't we just get along and be nice (as cheesy as it sounds)?" While her essay lacks rhetorical elegance she does pose an interesting question and she suggests that the Upanishads have complicated her thinking on the issue of empathy.

In a Krishnamurtian angle Kevin suggests that he "can't help but believe that everything is actually connected emotionally and a little bit physically. The issue is that our society, and when I say that I don't mean just the United States, I mean the population of the world, is so fragmented and individualized. People get so separated and put up walls around themselves on who they are, what they do, what they believe, who they don't like and so on. People can't see others past these walls and if you're not inside their wall with them you basically don't exist." This student's thinking illustrates well 
the world in which he lives. Further, his ability to creatively process this world through the lens of the texts read in this course offers an example of what can be accomplished when students negotiate their boundaries through the concepts presented in the work of J. Krishnamurti and the Upanishads.

Not every student found the course to be helpful as they processed the Upanishadic relationships between the self and the other. For example, Scott argues that the course offered pretty much what he "expected." He indicated that fixing the problems of the world cannot be accomplished because "human beings are what's wrong with the world and nothing will be fixed until we recognize that we are the problem." In a rather cynical moment he suggests that because people are involved, fixing problems is an impossibility. For him the texts and themes of the course were expected and the outcomes sought are an impossibility. Another student laments that she "really liked" the concept of changing the world but then she went on to argue "I think it is unrealistic to assume that even the majority of people in the world would submit to being totally respectful for nature and others." Her response illustrates the importance of studying the relationships between the self and the other through the theoretical lens of the Upanishads. Yet she could not make the conceptual leap to recognize the possibilities. For this student, human nature would ultimately win and thus empathic awareness is not possible. However, she seems to be open to the concepts herself. This student disagrees that changes in thinking occur at the level of the individual self.

In the final analysis, perhaps the greatest impact this process had is not on the students but on the teacher. The pedagogical goal now is to be empathically aware of not only the student's lives but also the people we study through time and space. The 
question before each lesson now becomes: "What would it be like today if His Holiness the Dalai Lama taught this lesson? Or Thomas Merton, or J. Krishnamurti?" 


\section{WORK CITED}

Abraham, Matthew. "Theory in the Corporate University." In Transforming English Studies: New Voices in an Emerging Genre. Lori Ostergaard, Jeff Ludwig, and Jim Nugent eds., West Lafayette, IN: Parlor Press, 2009.

Appelbaum, Peter Michael. Multicultural And Diversity Education: A Reference Handbook. Santa Barbara, CA: ABC-CLIO, 2002.

Armstrong, Karen. Twelve Steps to a Compassionate Life. New York: Alfred A. Knopf, 2011.

Balibar, Etienne. "Civic Universalism and its Internal Exclusions: The Issue of Anthropological Difference." Boundary 2 39:207-229, 2012.

Banks, James A.Banks, Cherry A. McGee., eds. Multicultural Education: Issues And Perspectives. New York: John Wiley \& Sons, 2001.

Barasch, Marc Ian. Field Notes on the Compassionate Life. New York: Rodale Books, 2005.

Bartholomae, David. "The Tidy House: Basic Writing in the American Curriculum." Journal of Basic Writing 12:4-22. 1993.

Berlin, B. and P. Kay. Basic Color Terms: their Universality and Evolution. Berkley: University of California Press, 1969.

Bhabha, Homi. The Location of Culture. London: Routledge, 1994.Bizzell, Patricia.

"Contact Zones and English Studies." In Cross-Talk in Comp Theory:

A Reader. Victor Villanueva ed. Urbana, IL: National Council of Teachers of English, 2003, 479-486.

Boast, Robin. "Neocolonial Collaboration: Museum as Contact Zone Revisited." Museum Anthropology 34:56-70, 2011.

Borg, Marcus. Jesus and Buddha: The Parallel Sayings. Berkley: Ulysses Press, 1997.

Broad, Bob. What We Really Value: Beyond Rubrics in Teaching and Assessing Writing. Logan, UT: Utah State University Press, 2003.

Canagarajah, A. Suresh. Resisting Linguistic Imperialism in English Teaching. Oxford: Oxford University Press, 1999.

Carter, Michael. "Stasis and Kairos: Principles of Social Construction in Classical Rhetoric. Rhetoric Review 7:97-112, 1988.

CCCC Committee on Assessment. "Writing Assessment: A Position Statement." CCC 46:3 (1995): 430-437.

Conway, Janet. "Cosmopolitan or Colonial? The World Social Forum as 'Contact Zone." Third World Quarterly 32:217-236, 2011.

Couture, Barbara. Toward a Phenomenological Rhetoric : Writing, Profession, and Altruism. Carbondale: Southern Illinois University Press, 1998.

Dalai Lama. Becoming Enlightened. New York: Atria Books, 2009.

--Ethics for the New Millennium. New York: Riverhead Books, 1999. 
--The Good Heart: A Buddhist Perspective on the Teachings of Jesus. Boston:

Wisdom Publications, 1996.

Davis, Andrew and Zach Parton. "The Risky Rubric in a Geography Course."

Progressive Measures 4:2 (2009), pp. 12-15.

Decety, Jean. "The Neuroevolution of Empathy." The Annals of the New York Academy of Sciences 1231:35-45, 2011.

Diogenes, Marvin and Andrea Lunsford. "Toward Delivering New Definitions of

Writing." In Delivering College Composition: The Fifth Canon. Kathleen Blake

Yancey ed. Boynton/Cook Publishing, 2006, pp. 141-154.

Durrant, Will. Our Oriental Heritage. New York: Simon and Schuster, 1935.

Easwaran, Eknath. The Upanishads. San Francisco: Nilgiri Press, 2007.

Elmborg, James. "Libraries in the Contact Zone: On the Creation of Educational Space." Reference \& User Services Quarterly 46: 56-64, 2006.

Emig, Janet. "Writing as a Mode of Learning." In Cross-Talk in Comp Theory: A Reader. Victor Villanueva ed. Urbana, IL: National Council of Teachers of English, 2003, pp. 7-16.

Fecho, Bob, JoBeth Allen, Claudia Mazaros, and Hellen Inyega. "Teacher Research in Writing Classrooms." In Research on Composition: Multiple Perspectives on Two Decades of Change. Peter Smagorinsky, ed. New York: Teachers College Press, 2006.

Flower, Linda. "Talking Across Difference: Intercultural Rhetoric and the Search for Situated Knowledge." CCC 55:1 (2003): 38-68.

Gallese, Vittorio and George Lakoff. "The Brain's Concepts: The Role of the SensoryMotor System in Conceptual Knowledge." Cognitive Neuropsychology 21:0 (2005): 1-25).

Gorski, Paul. Critical Multicultural Pavilion. http://www.edchange.org/multicultural/

Graff, Gerald. Clueless in Academe: How Schooling Obscures the Life of the Mind. New Haven: Yale University Press, 2003.

Guntern, Gottlieb. The Spirit of Creativity: Basic Mechanisms of Creative Achievements. Lanham, MD: University Press of America, 2010.

Hairston, Maxine. "Diversity, Ideology, and Teaching Writing." CCC 43:2 (1992): 179193.

Hamilton, Sue. Indian Philosophy: A Short Introduction. Oxford: Oxford University Press, 2001.

Hanson, James. "Was Jesus a Buddhist?" Buddhist-Christian Studies 25 (2005): 75-89.

Hawk, Byron. A Counter-History of Composition: Toward Methodologies of Complexity. Pittsburg: University of Pittsburg Press, 2007.

Heidegger, Martin. Being and Time. Albany: State University Press of New York. 1953.

Herman, A.L. An Introduction to Indian Thought. Englewood Cliffs, NJ: Prentice-Hall, 1976.

Hollan, Douglas. "Emerging Issues in the Cross-Cultural Study of Empathy." Emotion Review 4:70-78, 2012.

--"Being There: On the Imaginative Aspects of Understanding Others and Being Understood." Ethos 36:475-489, 2008.

Hollan, Douglas and Jason Throop. "Whatever Happened to Empathy? Introduction." 
Ethos 36:385-400, 2008.

hooks, bell. Teaching to Transgress: Education as the Practice of Freedom. London: Routledge, 1994.

Huot, Brian. "Toward a New Theory of Writing Assessment." CCC 47:4 (1996), 549566.

Huxley, Aldous. The Perennial Philosophy. New York: Harper Colophon Books, 1944. Iacoboni, Marco. Mirroring People: The Science of Empathy and How We Connect with Others. New York: Farrar, Straus and Giroux, 2008.

Jack, Jordynn and Gregory Appelbaum. "This is Your Brain on Rhetoric: Research Directions for Neurorhetorics." Rhetoric Society Quarterly 40:411-437, 2010.

Jensen, Derrick. Walking on Water: Reading, Writing, and Revolution. White River Junction, VT: Chelsea Green Publishing, 2004.

Keysers, Christian. "Mirror Neurons: Are We Ethical by Nature?" In What's Next? : Dispatches on the Future of Science : Original Essays from a New Generation of Scientists. Max Brockman ed. New York: Vintage, 2009.

King, Joyce Elaine, Hayman, Warren C.,Hollins, Etta R., eds. Preparing Teachers For Cultural Diversity. New York: Teachers College Press, 1997.

Kinneay, James. "Kairos: A Neglected Concept in Classical Rhetoric." In Rhetoric and Praxis. Jean Dietz Moss, ed. Washington, DC: The Catholic University of America Press, 1986.

Kiuhara, Sharlene, Leanne Hawken, and Steve Grahm. "Teaching Writing to High School Students: A National Survey." Journal of Educational Psychology 101:136-160, 2009.

Knitter, Paul. Without Buddha I Could Not Be A Christian. Oxford: Oneworld, 2009.

Krishnamurti, J. The First and Last Freedom. San Francisco: Harper, 1954.

--The Awakening of Intelligence. New York: Harper Collins, 1973.

--Total Freedom: The Essential Krishnamurti. San Francisco: Harper Collins, 1996.

--Freedom from the Known. San Francisco: Harper Collins, 1969.

--Education and the Significance of Life. New York: Harper One, 1953.

Kumar Lal, Basant. Contemporary Indian Philosophy. Delhi: Motilal Banarsidass, 1973.

Lakoff, George. The Political Mind: Why You Can't Understand 21st Century American Politics with an 18th Century Brain. New York: Viking, 2008.

Lakoff, George and Mark Johnson. Metaphors We Live By. Chicago: University of Chicago Press, 1980.

Leistyna, Pepi. Defining And Designing Multiculturalism: One School System's Efforts. Albany: State University Of New York Press, 2002.

Loewen, James. Teaching What Really Matters: How to Avoid the Tyranny of Textbooks and Get Students Excited About Doing History. New York: Teachers College Press, 2010

Lu, Min-Zhan. "Professing Multiculturalism: The Politics of Style in the Contact Zone." In Cross-Talk in Comp Theory: A Reader. Victor Villanueva ed. Urbana, Il: National Council of Teachers of English, pp. 487-503, 1994.

Lyotard, Jean-Francois. "An Answer to the Question, What is the Postmodern?" The 
Postmodern Explained: Correspondence 1982-85. Julian Pefanis and Morgan

Thomas eds. Minneapolis: University of Minnesota Press, 1992, 1-16.

Manathunga, Catherine. Research as an Intercultural 'Contact Zone."' Discourse:

Studies in the Cultural Politics of Education 30:165-177, 2009.

Manji, Irshad. The Trouble with Islam Today: A Muslim's Call for Reform in Her Faith.

New York: St. Martin's Griffin, 2003.

May, Rollo. The Courage to Create. New York: Norton, 1975.

--Man's Search for Himself. New York: Dell Publishing, 1953.

Mays, Chris and Julie Jung. "Priming Terministic Inquiry: Toward a Methodology of

Neurorhetoric." Rhetoric Review 31:41-59, 2012.

Merton, Thomas. Essential Writings. Maryknoll, NY: Orbis Books, 2000.

--Passion for Peace: The Social Essays. New York: Crossroads Publishing, 1995.

--The Asian Journal of Thomas Merton. New York: New Directions, 1968.

Murray, Donald. "Teaching Writing Your Way." In Adolescent Literacy: Turning

Promise Into Practice. Kylene Beers, Robert E. Probst, and Linda Rief eds.

Portsmouth, NH: Heinemann, 2007.

The National Writing Project and Carl Nagin. Because Writing Matters: Improving

Student Writing in Our Schools. San Francisco: John Wiley \& Sons, 2006.

Nhat Hanh, Thich. The Heart of the Buddha's Teaching. New York: Broadway Books, 1998.

--Living Buddha, Living Christ. New York: Riverhead Books, 1995.

Nhat Hanh, Thich and Daniel Berrigan. The Raft is not the Shore: Converstations

Toward a Buddhist-Christian Awareness. New York: Orbis Books, 1975.

Nieto, Soni. The Light In Their Eyes: Creating Multicultural Learning Communities.

New York: Teachers College Press, 1999.

--Affirming Diversity: The Sociopolitical Context Of Multicultural Education.

White Plains, NY: Longman Publishers USA, 1996.

Nikhilananda, Swami. “The Realistic Aspect of Indian Spirituality." In Philosophy and

Culture East and West. Charles Moore ed. Honolulu: University of Hawaii

Press, 1968, pp. 494-517.

Owens, Derek. Composition and Sustainability: Teaching for a Threatened Generation.

Urbana, IL: National Council of Teachers of English, 2001.

Pagels, Elaine. The Gnostic Gospels. New York: Vintage Books, 1979.

Panikkar, Raimundo. The Vedic Experience: An Anthology of the Vedas for Modern

Man and Contemporary Celebration. Delhi: Motilal Banarsidass, 1977.

Philo. The Works of Philo. C.D. Yonge, trans. New York: Hendrickson Publishers, 1993.

Pinker, Steven. The Stuff of Thought: Language as a Window Into Human Nature. New York: Viking, 2007.

Potter, Karl. Advaita Vedanta up to Samkara and his Pupils. Princeton: Princeton University Press, 1981.

Pratt, Mary Louise. "Arts of the Contact Zone." Profession 91:33-40, 1991.

Qualley, Donna. Turns of Thought: Teaching Composition as Reflexive Inquiry. Portsmouth: Boynton/Cook, 1997.

Radhakrishnan, Sarvepalli. "The Indian Approach to the Religious Problem.” In 
Philosophy and Culture East and West. Charles A. Moore ed. Honolulu: University of Hawaii Press, 1962, 255-262.

--A Sourcebook in Indian Philosophy. Princeton: Princeton University Press, 1957.

--The Philosophy of Radhakrishnan. New York: Tudor

Publishing, 1952.

--Eastern Religion \& Western Thought. Delhi: Oxford University Press, 1939.

--An Idealist View of Life. London: George Allen \& Unwin Ltd., 1932.

--Indian Philosophy, 2 vols. Delhi: Oxford University Press, 1923

Radhakrishnan, S. and Charles Moore. A Source Book in Indian Philosophy. Princeton: Princeton University Press, 1957.

Redd, Teresa. "Keepin' it Real: Delivering College Composition at an HBCU." In Delivering College Composition: The Fifth Canon. Kathleen Blake Yancey ed. Portsmouth, NH: Boynton/Cook, 2006, pp. 72-88.

Rifkin, Jeremy. The Empathic Civilization: The Race to Global Consciousness in a World in Crisis. New York: Penguin, 2009.

Rogers, Carl. Carl Rogers: The Man and His Ideas. New York: E.P. Dutton, 1975. --Freedom to Learn. Columbus, OH: Charles E. Merrill Publishing, 1969.

--On Becoming a Person. Boston: Houghton Mifflin, 1961.

Sánchez, Rául. The Function of Theory in Composition Studies. Albany: State University of New York Press, 2005.

Schopenhauer, Arthur. Essays and Aphorisms. New York: Penguin, 1970.

--On the Basis of Morality. Oxford: Berghahn Books, 1995[1839].

Sheard, Cynthia. "Kairos and Kenneth Burke's Psychology of Political and Social Communication." College English 55:291-310, 1993.

Sri Chinmoy. Commentaries on the Vedas, the Upanishads, and the Bhagavad Gita. New York: Aum Press, 1996.

Staudinger, Ursula, Anna Maciel, Jacqui Smith, and Paul Baltes. "What Predicts Wisdom-Related Performance? A First Look at Personality, Intelligence, and Facilitative Experiential Contexts.” European Journal of Personality 12 (1998): 1-17.

Strabo. Geography. Horace Leonard Jones, trans. Cambridge: Harvard Loeb Classical Library, 2006.

Stratton, Jon and Vijay Devadas. "Identities in the Contact Zone." Borderlands 9:1-7, 2010.

Subramanya, V. Iyer. Advaita: The Truth of Non-Duality. Rhinebeck, NY: Epigraph Publishing, 2009.

Tillich, Paul. Paul Tillich: Theologian of the Boundaries. Minneapolis: Fortress Press, 1987.

--The Shaking of the Foundations. New York: Charles Scribner's Sons, 1948.

Tingle, Nick. Self-Development and College Writing. Carbondale, IL: Southern Illinois University Press, 2004.

Vedaparayana, G. "The Conditioned and the Unconditioned Mind: J. Krishnamurti's Perspective." Indian Philosophical Quarterly 30:525-552.

Wiggins, Grant. "The Constant Danger of Sacrificing Validity to Reliability: Making Writing Assessment Serve Writers.” Assessing Writing 1:1 (1994), 129-139. 
Yancey, Kathleen. Writing in the 21st Century. Urbana: National Council of the Teachers of English, 2009.

--"Delivering College Composition into the Future." In Delivering College

Composition: The Fifth Canon. Kathleen Blake Yancey ed. Portsmouth, NH: Boynton/Cook Publishers, 2006, pp. 199-209.

--“Made Not Only in Words: Composition in a New Key." CCC 56:2 (2004), 297 328. 